\title{
HEARSAY EXCEPTIONS: ADJUSTING THE RATIO OF INTUITION TO PSYCHOLOGICAL SCIENCE
}

\author{
JOHN E.B. MYERS*, INGRID CORDON**, SIMONA GHETTI***, \\ AND GAIL S. GOODMAN****
}

\begin{abstract}
I
\section{INTRODUCTION}

Exceptions to the hearsay rule grew out of intuitive beliefs about human nature. ${ }^{1}$ Thus, dying declarations were thought to be reliable because dying declarants hesitate to meet their Maker with a lie upon their lips. ${ }^{2}$ Excited utterances are reliable because traumatic stress is believed to still the capacity to lie. Statements to doctors are trustworthy because patients are believed to have an incentive to tell the truth to the doctor. Psychological science based on empirical study of human behavior played no role in the origin of most hearsay exceptions. The exceptions, after all, came into being long before William James and Wilhem Wundt established their laboratories in 1875 and $1879 .^{3}$
\end{abstract}

Copyright (C) 2002 by John E.B. Myers, Ingrid Cordon, Simona Ghetti, and Gail S. Goodman

This article is also available at http://www.law.duke.edu/journals/65LCPMyers.

* Professor of Law, University of the Pacific, McGeorge School of Law, Sacramento, CA.

** Doctoral Student, Psychology, University of California, Davis.

*** Graduate Student, Psychology, University of California, Davis.

**** Professor of Psychology, University of California, Davis.

1. See 5 John H. Wigmore, Evidence in Trials at Common LaW $\S 1420$ (Chadbourn rev. 1974). In this treatise, Wigmore wrote:

We see that under certain circumstances the probability of accuracy and trustworthiness of statement is practically sufficient, if not quite equivalent to that of statements tested in the conventional manner [by cross-examination]. This circumstantial probability of trustworthiness is found in a variety of circumstances sanctioned by judicial practice; and it is usually from one of these salient circumstances that the exception takes its name. There is no comprehensive attempt to secure uniformity in the degree of trustworthiness which these circumstances presuppose. It is merely that common sense and experience have from time to time pointed them out as practically adequate substitutes for the ordinary test, at least, in view of the necessity of the situation. $I d$. at $\S 1422$.

2. The dying declaration exception dates back to the 1700s. See 5 Wigmore, supra note 1 , at $\S$ 1430. Wigmore notes that all courts have agreed, with more or less difference of language, that the $a p$ proach of death produces a state of mind in which the utterances of the dying person are to be taken as free from all ordinary motives to misstate. Id. at $\S 1438$; see also id. at $\S 1423, \S 1443$.

3. See 5 WigmORE, supra note 1 , at $\S 1426$ ("It can be said definitely that most of the exceptions began to be recognized during the 1700 s, and that the few remaining ones were not recognized until the $1800 \mathrm{~s}$; but that is all."). 
Today, psychological science has made tremendous progress, and it is appropriate to ask whether modern psychology supports or undermines the intuitive foundations of hearsay exceptions. This paper explores this issue by examining three exceptions: excited utterances, statements for purposes of medical diagnosis or treatment, and the residual hearsay exception. These selections are appropriate because the focus is child declarants, and these exceptions play key roles in child abuse litigation.

\section{THE EXCITED UTTERANCE EXCEPTION}

The origins of the excited utterance exception can be traced to the eighteenth century. ${ }^{4}$ The exception is invoked frequently in child abuse litigation. ${ }^{5}$ The exception is codified in Rule 803(2) of the Federal Rules of Evidence, which provides that the hearsay rule does not exclude statements "relating to a startling event or condition made while the declarant was under the stress of excitement caused by the event or condition." "The primary rationale for the exception is that statements are trustworthy when made shortly following a startling event and while the declarant remains affected by the stress caused by the event. Traumatic stress is thought to lower the probability that statements are a product of conscious fabrication. ${ }^{7}$

The excited utterance exception has three requirements. First, there must be an exciting event. Second, the out-of-court statement must relate to the event. Third, the statement must be made while the declarant is under the stress of excitement induced by the event.

Courts consider several factors to determine whether hearsay statements were made under the stress of excitement caused by a startling event. We discuss these factors below, employing a two-step process. We begin by outlining legal principles. The legal analysis will then be followed by relevant psychological principles. We conclude the discussion of excited utterances by grappling with the fundamental question: Does traumatic stress still the capacity to lie?

Some of the legal factors involved in this determination include:

4. 6 WIGMORE, supra note 1 , at $\S 1747$.

5. For a collection of cases on the excited utterance exception in child abuse litigation see 2 JOHN E.B. Myers, Evidence in Child ABuse \& Neglect CASES $§$ 7.32-7.33 (3d ed. 1997 and 2001 Cumulative Supplement).

6. FED R. EVID 803(2).

7. See 6 Wigmore, supra note 1 , at $\S 1747$, in which Wigmore wrote:

This general principle is based on the experience that, under certain external circumstances of physical shock, a stress of nervous excitement may be produced which stills the reflective faculties and removes their control, so that the utterance which then occurs is a spontaneous and sincere response to the actual sensations and perceptions already produced by the external shock. Since this utterance is made under the immediate and uncontrolled domination of the senses, and during the brief period when considerations of self-interest could not have been brought fully to bear by reasoned reflection, the utterance may be taken as particularly trustworthy (or at least as lacking the usual grounds of untrustworthiness), and thus as expressing the real tenor of the speaker's belief as to the facts just observed by him; and may therefore be received as testimony to those facts. 
Spontaneity. For many courts, spontaneity is the most important factor in determining whether a statement was a product of reflective thought or a spontaneous reaction to a startling event. The more spontaneous the statement, the more likely the court is to apply the excited utterance exception. If a child had an opportunity to reflect, the balance tips away from admissibility.

Questioning. A child may make a statement in response to questions about a startling event. Courts agree that questioning does not necessarily destroy the excitement required for this exception. Thus, simple questions like "What happened?" do not destroy excitement or spontaneity. As questioning increases, however, and especially as questions become suggestive, the odds decrease that the child's statement is a spontaneous reaction to a startling event.

Lapse of time. The longer the delay between a startling event and an out-ofcourt statement, the less likely the declarant was excited when the statement was made. Courts agree, however, that lapse of time is not dispositive on the question of excitement. Delay is considered in relation to other factors shedding light on excitement. Several decisions state that when the declarant is a young child, longer delay is allowable. Courts approve delays ranging from a few minutes to many hours. At the same time, courts reject statements when delay and other factors indicate lack of excitement.

Emotional Condition. A child's emotional condition is important in evaluating whether a statement was made under the stress of a startling event. If the child was visibly upset or crying, the court is more likely to conclude the statement is an excited utterance. On the other hand, if the child was calm when the out-of-court statement was made, or if periods of calm or sleep intervened, the statement is less likely to gain admission.

Physical Condition. A child's physical condition may indicate excitement. For example, if a child is injured or in pain, the child's statements may be excited.

Speech pattern. The manner in which a child makes a statement may indicate excitement. For example, pressured or hurried speech may indicate excitement. The words themselves also may evidence excitement.

Age. A number of decisions indicate sensitivity to the age of children who make statements relating to startling events. The decisions suggest a belief that younger children may be more excited by certain events than adolescents.

We now turn to the psychological aspects of the excited utterance exception. In this section, we do not address every factor governing decisions about whether the excited utterance exception may apply because, to our knowledge, psychological research has never directly tested the hypothesis that stress inhibits the ability to lie. Given the lack of empirical research directly on point, we must conclude that, although the logic underlying the excited utterance exception is intuitively appealing, there is no empirical, scientifically sound evidence to support it. Implied in the excited utterance exception, however, are two assumptions regarding psychological processes that have been studied by psychologists. 
The first assumption is that stress disrupts the ability to perform mental tasks efficiently. Specifically, when a person experiences stress, particularly traumatic stress, the person may be less able to focus on the task demanded, that is, less able to concentrate on performance. The second assumption is that lying is an effortful behavior that has mental costs. To be believed, a liar must provide a plausible story, consistent with what he or she has already reported about the alleged event, a story that — to be believed-should be told with a great deal of spontaneity. Thus, a liar is required to expend mental resources to lie successfully. If we consider more generally these two assumptions about psychological processes underlying the excited utterance exception, then psychology may provide some useful information to the legal system.

\section{A. Assumption 1: Stress Disrupts the Ability to Perform Cognitive Tasks Efficiently}

Psychological researchers have studied the effects of stress on several complex cognitive tasks, such as decision-making, reasoning, and problem-solving. It has often been demonstrated that performance suffers if individuals are exposed to stressful conditions. For instance, Keinan, Friedland, and Ben-Porath studied the effect of the threat of electric shock on adults' performance in a multiple-choice analogy test. ${ }^{8}$ These researchers found that the multiple-choice alternatives were not covered in a systematic manner, resulting in lower levels of performance. Similar disruptive effects have been found by exposing individuals to dangerous or stressful environments (e.g., deep-sea diving, parachuting, speaking in public), ${ }^{9}$ putting individuals in overly crowded or heated places, ${ }^{10}$ or causing fatigue or sleep deprivation. Many other stressors along these lines also tend to decrease performance in a variety of tasks (from simulated-military decision making to attention tasks). ${ }^{11}$ However, decrements in performance are also related to the ease of the task and to the extent of practice a person has with a task, such that stress is less likely to disrupt easier and more practiced tasks. Most studies on stress and performance have been conducted with adults (as well as with animals), as opposed to children. ${ }^{12}$ Based on developmental theory generally, ${ }^{13}$ one would predict that young children would have

8. See generally Giora Keinan et al., Decision Making Under Stress: Scanning of Alternatives Under Physical Threat, 64 ACTA PSYCHOLOGICA 219 (1987).

9. See Chris Idzikowski \& Alan Baddeley, Waiting in the Wings: Apprehension, Public Speaking and Performance, 26 ERGONOMICs 575, 583 (1983).

10. See James Shanteau \& Geri A. Dino, Environmental Stressor Effects on Creativity and Decision Making, in Time Pressure AND Stress in Human JudgMent AND Decision MaKing 293 (Ola Svenson \& A. John Maule eds., 1993).

11. See generally Kenneth R. HAMmond, Judgment Under STRESS (2000).

12. Some of the few studies on stress and performance carried out with children concern test anxiety and performance. In these studies, children are often divided into high and low anxiety groups, based on measures of anxiety, and their performance is then examined on various types of academic tests. See James Plass \& Kennedy Hill, Children's Achievement Strategies and Test Performance: The Role of Time Pressure, Evaluation Anxiety, and Sex, 22 DEV. PSYCH. 31 (1986).

13. See generally Robbie Case, THE MIND's STAIRCASE: EXPLORING CONCEPTUAL UNDERPINNINGS OF CHILDREN's THOUGHT AND KNOWLEDGE (1991); Kurt W. Fischer, A Theory of 
greater difficulty than adults at mentally coordinating the emotion involved in a startling event, on the one hand, and intentional lying, on the other hand.

Thus, although the scientific evidence is indirect, it points to the possibility that the legal assumption underlying the excited utterance exception may generally be correct, especially for young children.

\section{B. Assumption 2: Efficient Lying Requires Mental Effort}

Another area of psychological research relevant to assumptions underlying the excited utterance exception concerns whether lying requires mental effort. Although research on children's ability to lie is reviewed later in this article, suffice it to say now that lying, especially telling complex lies, can take mental effort (at least to lie well). Consider the results of an experiment conducted by Aldert Vrij and colleagues. ${ }^{14}$ These researchers compared the quality (e.g., amount and vividness of detail) and believability of statements by individuals who were asked to tell the truth versus individuals who were asked to lie. Individuals were required to describe a theft they had seen on videotape. Information was elicited with open-ended questions. Only fifteen seconds before the beginning of the interview, individuals assigned to the deception condition were asked to lie about what they had seen. Under these circumstances, several behavioral indicators (e.g., hand/finger movements, "ah" speech disturbances, latency periods) reliably distinguished liars from truth tellers. Also, when the statements were analyzed for content, the true statements were of higher quality (e.g., more detailed) than the false statements. The authors concluded that being required to lie spontaneously without preparation is a difficult task. Such difficulty reflects cognitive load and emotional discomfort. ${ }^{15}$ Similar conclusions have been drawn when comparing the ability to detect high-stake lies versus low-stake lies: The former have been found easier to detect than the latter because liars display behavioral signs of emotion and cognitive load. ${ }^{16}$ Research in this area with child participants is sparse. The few studies conducted with child participants reveal that children show behavioral patterns similar to those observed in adults. ${ }^{17}$

Cognitive Development: The Control and Construction of Hierarchies of Skills, 87 PsYCHOLOGICAL ReVIEW 477 (1980); Jean Piaget, Piaget's Theory, in HANDBOOK OF CHILD Psychology 103 (Paul Mussen ed., 1983).

14. See Aldert Vrij et al., Detecting Deceit Via Analysis of Verbal and Nonverbal Behavior, $24 \mathrm{~J}$. NONVERBAL BEHAV. 239, 264 (2000).

15. Cognitive load refers to the total amount of mental activity imposed on active memory at an instant in time. The major factor that contributes to cognitive load is the number of elements to which a person needs to attend.

16. See Paul Ekman \& Mark G. Frank, Lies that Fail, in LYING AND DECEPTION IN EVERYDAY LIFE 184, 200 (Michael Lewis \& Carolyn Saarni eds., 1993); see also Mark G. Frank \& Paul Ekman, The Ability to Detect Deceit Generalizes Across Different Types of High-Stake Lies, 72 J. PERSONALITY \& SOCIAL PSYCH. 1429 (1997).

17. See Aldert Vrij \& Frans Willem Winkel, Detection of False Statements in First and Third Graders: The Development of a Nonverbal Detection Instrument, in PSYCHOLOGY, LAW, AND CRIMINAL JUSTICE: INTERNATIONAL DEVELOPMENTS IN RESEARCH AND PRACTICE 221, 230 (Graham Davies \& Sally Lloyd-Bostock eds., 1995). 
Overall, these studies suggest that lying may be a difficult task, particularly when individuals are not prepared to lie or are required to deceive regarding important issues. The difficulty of lying may be further increased, as happens for other cognitive tasks, by stressful circumstances. It should be emphasized, however, that individuals in the studies reported here were still capable of fabricating lies even under non-optimal conditions, although they did so less efficiently. Future research should establish the extent to which the ability to lie is compromised by stress, including traumatic stress, especially for children.

The heart of the excited utterance exception is the belief that traumatic stress inhibits lying. ${ }^{18}$ On this key point, psychology has little direct evidence, although there is indirect evidence indicating that individuals may lie with more difficulty under stressful circumstances, as demonstrated by the fact that liars are easier to catch under those circumstances. There is no evidence, however, that trauma momentarily stills the capacity or motivation to lie. The idea has intuitive appeal. Yet, at least for the time being, the theory underlying the excited utterance exception must remain just that, a theory, unsupported by empirical evidence. When it comes to excited utterances, modern research does little to alter the ratio of intuition to psychological science.

III

\section{THE MedicAl Diagnosis OR TREATMENT EXCEPTION}

Certain hearsay statements made for purposes of obtaining treatment or a diagnosis are thought to be sufficiently reliable to be admitted as evidence. ${ }^{19}$ Statements to physicians providing treatment have long been admitted. ${ }^{20}$ Under Federal Rule of Evidence 803(4), statements for purposes of diagnosis alone are

18. The excited utterance exception has never been short of critics. See, e.g., Angela Conti \& Brian Gitnik, Comment, Federal Rule of Evidence 803(2): Problems with the Excited Utterance Exception to the Rule on Hearsay, 14 ST. JOHN's J. LEGAL COMMENT. 227, 250 (1999) ("Stress does not prevent fabrication or inaccuracies. Stress does, however, lead to distortion, confusion, and misperception."); Robert M. Hutchins \& Donald Slesinger, Some Observations on the Law of Evidence: Spontaneous Explanations, 28 COLUM. L. REV. 432, 439 (1928) ("What the emotion gains by way of overcoming the desire to lie, it loses by impairing the declarant's power of observation."); I. Daniel Stewart, Perception, Memory, and Hearsay: A Criticism of Present Law and the Proposed Federal Rules of Evidence, 1970 UTAH L. REV. 1, 28 (1970).

19. In this article, we do not address the difficult issue of the application of the medical diagnosis or treatment exception to children's statements to psychotherapists. For a discussion of this issue, see 4 Christopher B. Mueller \& LAIRD C. KIRKPATRICK, FEDERAL EVIDENCE $§ 442$ (2d ed. 1994); 2 JOHN E.B. MYERS, supra note 5, at § 7.39; John J. Capowski, An Interdisciplinary Analysis of Statements to Mental Health Professionals Under the Diagnosis or Treatment Hearsay Exception, 33 GA. L. REV. 353 (1999); Robert P. Mosteller, Child Sexual Abuse Accusations and Statements for the Purpose of Medical Diagnosis or Treatment, 67 N.C. L. REV. 257 (1989).

20. See FED. R. EVID. 803(4) advisory committee's note ("Even those few jurisdictions which have shied away from generally admitting statements of present condition have allowed them if made to a physician for purposes of diagnosis and treatment in view of the patient's motivation to be truthful."); see also 4 MUELLER \& KIRKPATRICK, supra note 19, at $\S 442 ; 6$ WIGMORE, supra note 1, at $§ 1722$ (discussing the origins of the exception). 
also admissible. ${ }^{21}$ Most states have a version of this exception, although states vary in the detail. ${ }^{22}$ Federal Rule 803(4) provides:

The following are not excluded by the hearsay rule, even though the declarant is available as a witness: Statements made for purposes of medical diagnosis or treatment and describing medical history, or past or present symptoms, pain, or sensations, or the inception or general character of the cause or external source thereof insofar as reasonably pertinent to diagnosis or treatment. ${ }^{23}$

The primary rationale supporting the diagnosis or treatment exception is the belief that statements to physicians are reliable because the patient has an incentive to be truthful with the doctor. ${ }^{24}$ The patient's health-even life-may depend on the information supplied to the doctor. This "patient incentive" rationale exists, of course, only if the patient appreciates the clinical significance of candor.

In addition to the patient incentive rationale, two intertwined subsidiary rationales have been offered to support the exception. The first may be called the "Doctors are smart" rationale. The second is the "They're gonna hear it anyway" rationale.

\section{A. The "Doctors Are Smart" Rationale}

Doctors are smart. Moreover, doctors are motivated to diagnose correctly. Because doctors are smart and highly motivated to "get it right," doctors are able - so the theory goes - to listen to patients, sort wheat from chaff, and incorporate only the former into diagnostic decisions. Thus, because doctors have special skill in assessing patient statements, hearsay relied on by doctors is sufficiently reliable to be admitted in evidence. Robert Mosteller points out elsewhere in this issue that there is no particular reason to think doctors are better than others at differentiating true from false statements. ${ }^{25}$ Certainly, no empirical evidence supports the idea that doctors are "smarter" than others in this regard.

21. FED. R. EVID. 803(4).

22. See Robert P. Mosteller, The Maturation and Disintegration of the Hearsay Exception for Statements for Medical Examination in Child Sexual Abuse Cases, 65 LAW \& CONTEMP. PROBS. 47 (2002).

23. FED. R. EVID. 803(4).

24. See Meany v. United States, 112 F.2d 538, 539-40 (2d Cir. 1940) ("A man goes to his physician expecting to recount all that he feels, and often he has with some care searched his consciousness to be sure that he will leave out nothing. If his narrative of present symptoms is to be received as evidence of the facts, as distinguished from mere support for the physician's opinion, these parts of it can only rest upon his motive to disclose the truth because his treatment will in part depend upon what he says."); see also 4 MUELLER \& KIRKPATRICK, supra note 19, at $\$ 442$.

25. See Mosteller, supra note 22, at 62; see also L. Timothy Perrin, Expert Witnesses Under Rules 703 and 803(4) of the Federal Rules of Evidence: Separating the Wheat from the Chaff, 72 IND. L. J. 939, 961-62 (1997) ("No traditional exception to the hearsay rule relies solely on the person receiving the statement to supply the heightened trustworthiness needed."). 


\section{B. The "They're Gonna Hear It Anyway" Rationale}

Rule 803(4) admits statements to physicians providing diagnosis only, without treatment. One type of "diagnosis only" doctor is a doctor retained to examine an injured litigant, diagnose the patient/litigant's condition, and provide expert testimony. In reaching a diagnosis, the doctor/expert talks to the patient/litigant and considers the patient's statements. Of course, a patient who retains a physician to provide expert testimony may lack an incentive to tell the truth. $^{26}$ Indeed, the patient's motivation may point in the opposite direction, toward exaggerated suffering. With the primary rationale for this exception in doubt, why admit statements to diagnosticians retained to provide expert testimony? The doctor/expert satisfies the "Doctors are smart" rationale, but that is not the explanation. The drafters of Rule 803(4) apparently reasoned as follows. Under Rule 703, the jury will hear the doctor/expert's diagnosis and the data supporting it, including the patient/litigant's out-of-court statements. ${ }^{27} \mathrm{Un}$ der Rule 703, out-of-court statements supporting expert testimony are not offered for the truth of the matter asserted. The statements can be considered only insofar as they shed light on the expert's testimony. ${ }^{28}$ Upon request, the jury is instructed that it may not consider the statements for the truth. Yet, once the jury hears the patient's out-of-court statements, it is unrealistic to expect them to ignore them. ${ }^{29}$ For one, you can't unring the bell. ${ }^{30}$ Jurors are more

26. See 4 MUELLER \& KIRKPATRICK, supra note 19, at $\S 442$ ("Statements for purposes of diagnosis offer no similar assurance of candor.").

27. FED. R. EVID. 703 (requiring a balancing process when data supporting an expert opinion is otherwise inadmissible).

28. See 6 WigmORE, supra note 1 , at $\S 1720$. There, Wigmore writes:

A physician testifying as to a patient's health may be asked, like any other witness, for the reasons for his conclusions - either on direct examination, to show his opinion well founded, or on cross-examination, to show it ill founded; and incidentally the fact that it is in part or entirely founded on the statements of the patient or of others may thus be brought out. Here, of course, the patient's statement has no hearsay quality; without regard to its correctness or incorrectness, it enters merely as an observed fact forming part of the physician's data. It is possible to bring it forward in a testimonial shape; nevertheless, it is also possible, up to a certain point, to treat it merely as a fact affecting the weight of the physician's opinion.

Id.

29. See L. Timothy Perrin, supra note 25, at 940 ("[T]he [drafters concluded] that jurors were unlikely to make the subtle distinction between statements admitted under rule 703 for the sole purpose of explaining the expert's opinion and the substantive use of the same statements for the truth of the matter asserted."); see also JOHN W. STRONG, MCCORMICK ON EVIDENCE § 324.3 (5th ed. 1999) ("Unfortunately, although limiting instructions are appropriate and required when requested, jurors may be unable or unwilling to follow them.").

30. FED. R. EVID. 803(4) advisory committee's note, provides:

Conventional doctrine has excluded from the hearsay exception, as not within its guarantee of truthfulness, statements to a physician consulted only for the purpose of enabling him to testify. While these statements were not admissible as substantive evidence, the expert was allowed to state the basis of his opinion, including statements of this kind. The distinction thus called for was one most unlikely to be made by juries. The rule accordingly rejects the limitation. This position is consistent with the provision of Rule 703 that the facts on which expert testimony is based need not be admissible in evidence if of a kind ordinarily relied upon by experts in the field.

Id. 
likely to ignore the judge's limiting instruction. So, since "they're gonna hear the statements anyway" as support for the expert's opinion, the drafters decided the statements should be admissible both to support the expert's opinion and for the truth of the matter asserted.

The "they're gonna hear it anyway" rationale hardly seems an adequate basis for a hearsay exception. One need resort to this rationale only when out-ofcourt statements do not qualify for admission in some other way. Thus, if statements qualify under the legitimate "patient incentive" rationale or the dubious "doctors are smart" rationale, the statements are admissible because they possess indicia of reliability. On the other hand, statements admitted under the "they're gonna hear it anyway" rationale lack indicia of reliability. The recent amendment to Rule 703 reflects the concern that jurors can be misled by inadmissible information supporting expert opinion, and the revision of Rule 703 may solve the problem. If not, Rule 803(4) should be amended to eliminate statements to physicians consulted only to provide expert testimony.

C. The Eighth Circuit's Approach: $1+1=1$

In United States v. Iron Shell, the Eighth Circuit combined the "patient incentive" and the "doctors are smart" rationales into a single two-part test." The court described its test in United States v. Renville, where the court wrote that "first, the declarant's motive in making the statement must be consistent with the purposes of promoting treatment; and second, the content of the statement must be such as is reasonably relied on by a physician in treatment or diagnosis." 32

We refer to the Eighth Circuit's approach as $1+1=1$. Insofar as the court requires patient incentive, the court is on the right track. As discussed above, however, the "doctors are smart" rationale is dubious. Thus, when the "patient incentive" rationale is added to the "doctors are smart" rationale, the sum is one legitimate rationale, not two; hence $1+1=1$.

D. One and Only One Legitimate Rationale for 803(4)

We believe "patient incentive" is the only legitimate rationale supporting Rule 803(4). Hearsay exceptions are created because certain hearsay is reliable. Statements for purposes of diagnosis or treatment are reliable if the patient has an incentive to tell the truth. The alternative rationales discussed above simply do not hold water. The medical diagnosis or treatment exception should apply only when the declarant appreciates the clinical importance of candor. This is not to say the patient must fully comprehend the clinical implications of what is said. Few adults, let alone children, fully appreciate the clinical implications of their interactions with doctors. All that should be required is a showing that the

31. See United States v. Iron Shell, 633 F.2d 77, 84 (8th Cir. 1980).

32. See United States v. Renville, 779 F.2d 430, 436 (8th Cir. 1985). 
declarant had an understanding of the clinical importance of candor-an understanding that signals an incentive to tell the truth.

\section{E. Do Children Understand the Clinical Importance of Candor with Doctors?}

Rule 803(4) should not apply where a child-or an adult-lacks an understanding of the clinical importance of candor that is sufficient to signal an incentive to tell the truth. Absent clinical understanding, the statements may find their way into evidence through another exception, but not Rule 803(4). Thus, we come to the heart of the matter: Do children understand the clinical importance of candor with doctors? The answer is: It depends on the child. Some children possess the necessary understanding; others do not. Age alone is not a reliable marker, although it is difficult to imagine a two-year-old with the necessary understanding. With children older than two, however, case-by-case assessment is required. The four-year-old in one hospital bed may understand quite well the need to tell the truth, while the ten-year-old in the next bed does not comprehend the concept.

The medical and psychological literature contains relevant information about children's understanding of illness, routine medical care, and the role of medical professionals. From birth, most children in the United States have frequent interactions with doctors and nurses in the course of health care maintenance and in the provision of treatment for common childhood illnesses. Janice Genervo and her colleagues ${ }^{33}$ suggest that, because children's contacts with routine medical care typically begin early in our society, occur frequently during early childhood, and can at times be distressing, these experiences are likely to be salient and therefore play an integral part in the development of illness and medical representations.

As one would expect, children's understanding of illness, medical care, and medical personnel follows a developmental progression. ${ }^{34}$ In general, older children's understanding of illness and its causes is more complex and broader than that of younger children. Preschoolers in one study, for example, understood that doctors "look at you" and "fix-up," but most did not know the role nurses play in medical interactions. ${ }^{35}$ Second-graders, on the other hand, were able to provide more details about the roles of doctors and nurses than preschool children. ${ }^{36}$ Julie Hergenrather and Mitchell Rabinowitz found that younger children believed that changes in behavior, not symptoms, signaled ill-

33. See generally Janice L. Genevro et al., Young Children's Understanding of Routine Medical Care and Strategies for Coping with Stressful Medical Experiences, in CHILD DEV. \& BEHAV. PEDIATRICS 59 (Marc Bornstein \& Janice Genervo eds., 1996).

34. See generally Daniel J. Burbach \& Lizette Peterson, Children's Concepts of Physical Illness: A Review and Critique of the Cognitive-Developmental Literature, 5 HEALTH PSYCHOL. 307 (1986); Ellen C. Perrin \& Susan Gerrity, There's a Demon in Your Belly: Children's Understanding of Illness, 67 PEDIATRICS 841 (1981); Caroline C. Redpath \& Cosby S. Rogers, Healthy Young Children's Concepts of Hospitals, Medical Personnel, Operations, and Illness, 9 J. PEDIATRIC PSYCHOL. 29 (1984).

35. See Redpath \& Rogers, supra note 34, at 29-40.

36. Id. 
ness, whereas older children understood that symptoms often signal the presence of disease. ${ }^{37}$ In a review of the literature on children's concepts of illness, Daniel Burbach and Lizette Peterson found that older children conceptualized illness in terms of specific symptoms and diseases, whereas younger children conceptualized illness in more global terms and in nonspecific ways. ${ }^{38}$ Older children were also more aware of the psychological, affective, and social aspects of illness than were younger children.

Even young children, however, can demonstrate a fairly accurate understanding about basic medical care, illness, and coping strategies. Roger Bibace and James Dillon observed in their study that young children frequently stated that medicines are "good" because they make you feel better, that there are both "good drugs" and "bad drugs," and that there is a difference between medicines for children and medicines for adults. ${ }^{39}$ In a study examining young children's understanding of routine medical care and strategies for coping, Janice Genervo and colleagues found that, in general, four-year-old children's understanding of routine medical visits often includes information about various procedures as well as affective responses. ${ }^{40}$ Gender differences were also observed, indicating that girls' understanding of going to the doctor is significantly more complex than that of boys. Additionally, children were aware of various strategies for coping with potentially distressing medical experiences.

Although young children have been found to demonstrate developmentally advanced forms of reasoning about illness, children often rely on less mature forms of reasoning. ${ }^{41}$ Children often confuse the effects of a medicine with the effects of the disease. ${ }^{42}$ Caroline Redpath and Cosby Rogers report that several preschoolers in their study thought that people got sick or hurt in the hospital and that doctors were the cause of illness. ${ }^{43}$

An illustration from the writing of psychologist Margaret Steward provides insight into young children's limited understanding. Steward describes threeyear-old Sammy, who was knocked off his tricycle by a passing car, causing a concussion and fractured skull. When Steward visited Sammy in the pediatric ward, he was a solemn little boy. Steward talked with Sammy about being in the hospital, and asked, "Are the doctors helping you get well?" Sammy re-

37. See generally Julie R. Hergenrather \& Mitchell Rabinowitz, Age-Related Differences in the Organization of Children's Knowledge of Illness, 27 DEV. PSYCHOL. 952 (1991).

38. See Burbach \& Peterson, supra note 34, at 307-25.

39. See generally Roger Bibace \& James J. Dillon, What Children Want to Know About Medicine, in PARTNERships in Research, Clinical, And Educational SETtings 63 (Roger Bibace et al. eds., 1999).

40. See Genervo et al., supra note 33, at 59-83.

41. See generally Roger Bibace et al., Toward a Coexistence Concept of Causal Reasoning About Illness in Children and Adults, in PARTNERSHIPS IN RESEARCH, CLINICAL, AND EDUCATIONAL SETTINGS 27 (Roger Bibace et al. eds., 1999).

42. See Bibace et al., supra note 39, at 67.

43. See Redpath \& Rogers, supra note 34. 
plied, "No, the doctors are berry mean." were "helpers." Sammy's confusion is easy to comprehend. The nursing staff was ever-present and undoubtedly kind and nurturing. Sammy had a warm relationship with his nurses. Doctors, by contrast, rush in unexpectedly, poke and prod, stick you with things, ask questions, and then dash away without forming much of a relationship. Little wonder Sammy viewed the nurses as his only helpers.

Steward offers another illustration of the limits of young children's understanding. In a study of kindergartners and third-graders, Steward found that, although most kindergartners knew that a hypodermic syringe was used to give shots, many did not understand why shots were given. By contrast, most thirdgraders, that is, eight- and nine-year-olds, knew shots were given to prevent or cure illness. $^{45}$

At times, children may misunderstand the purpose of medical procedures. Some three- to six-year-olds, for instance, believe that medical procedures are administered as punishment. ${ }^{46}$ Ellen Perrin and Susan Gerrity wrote that "[c]hildren's ideas regarding illness frequently involve punishment, guilt, and self-blame.... Hospitalized children often ascribe the cause of their illness to disobedience of parental commands and interpret their hospitalization as rejection or punishment." ${ }^{47}$ Daniel Burbach and Lizette Peterson observed that "[o]lder, less anxious, and cognitively mature children seemed to reject the notion that illness and misbehavior are related. Younger, highly anxious, and less cognitively mature children did perceive of illness in a moralistic way and, furthermore, exhibited more self-blame for the etiology of illness." ${ }^{48}$ In contrast, John Taplin and his colleagues found that young children have a basic understanding of pain and its causes. In a study concerning children's understanding of pain, Taplin and his colleagues wrote that, for children as young as five, "pain is less likely to be regarded as a form of punishment for wrongdoing than as due to a biological or physical/behavioral cause, even by younger children." ${ }^{49}$ Taplin concluded that "from a relatively young age [children] have acquired a basic understanding of pain as a biological phenomenon and already know a little about how it may be caused." ${ }^{50}$

44. See generally Margaret Steward \& David Steward, Children's Conceptions of Medical Procedures, in NEW DiRECTIONS FOR CHILD DEVElopMENT: CHILDREN's CONCEPTIONS OF HEALTH, ILLNESS, AND BODILY FUNCTIONS 67 (Roger Bibace \& Mary E. Walsh eds., 1981).

45. See Margaret Steward \& Gary Regalbuto, Do Doctors Know What Children Know?, 45 AM. J. ORTHOPSYCHIATRY 146, 146-48 (1975).

46. See generally Roger Bibace \& Mary E. Walsh, Children's Conceptions of Illness, in NEW DiRECTIONS FOR CHILD DEVELOPMENT: CHILDREN'S CONCEPTIONS OF HEALTH, ILLNESS, AND Bodily FunCtions 31 (Roger Bibace \& Mary E. Walsh eds., 1981); Arlene B. Brewster, Chronically Ill Children's Concepts of Their Illness, 69 PEDIATRICs 355 (1982); see also Burbach \& Peterson, supra note 34 , at 307-25 Perrin \& Gerrity, supra note 34, at 841-49;.

47. Perrin \& Gerrity, supra note 34.

48. Burbach \& Peterson, supra note 34.

49. John E. Taplin et al., Children in Pain, in ChILdRen's Understanding OF Biology AND Health 131, 134 (Michael Siegal \& Candida C. Peterson eds., 1999).

50. Id. at 151 . 
A recent study by Pamela Kato, Thomas Lyon, and Christina Rasco, which reflects positively on children's developing understanding, suggests that earlier studies may have underestimated children's understanding and reasoning abilities concerning illness and punishment. ${ }^{51}$ Kato, Lyon, and Rasco wrote that "when children as young as 4 years of age are asked to recognize the causes of illness rather than to generate explanations, they show impressive understanding. ... As in many contexts, children can recognize what they cannot articulate. ${ }^{, 52}$ Further, the authors note that:

In this study, with a simplified interview technique, three-year-olds, especially healthy three-year-olds, showed impressive abilities to distinguish illness concepts from moral concepts: four-year-olds showed even more impressive abilities. This is not consistent with a large body of research that documents a developmental progression in children's understanding of causal mechanisms and moral blame. This research claims that children as young as three and four years of age are unable to understand causal mechanisms and to assign moral blame. The children in our study displayed these abilities when asked to distinguish illness and treatment from moral transgressions. ${ }^{53}$

In addition, Kato and her colleagues found that "[c]hildren who show imminent justice reasoning believe Nature is capable of seeking retribution for misdeeds, and they might also think that Nature intends to punish "naughty" children with illness. ... Our data do not support the claim that children think that illness and treatment are a form of imminent justice. Our data do support the claim that children have difficulty distinguishing illness and treatment from punishment." ${ }^{54}$ They explained that, "[c] onsistent with other research that uses a simplified interview methodology, we found that significant numbers of young children were able to show sophisticated reasoning skills concerning illness and immorality when they are asked to recognize rather than generate reasons for illness and treatment." 55 Finally, they stated that these findings "do not support the current theory that claims that very young children have a primitive understanding of the concepts of illness and treatment.... Children as young as three and four years old in our study who were given simplified tasks and asked to distinguish between immoral and ill characters were surprisingly proficient at doing so." 56

The psychological literature suggests that young children do have a basic understanding of the need to provide accurate information to healthcare providers. Melody Herbst and her colleagues examined three- to six-year-old chil-

51. See generally Pamela M. Kato et al., Reasoning About Moral Aspects of Illness and Treatment by Preschoolers Who are Healthy or Who Have Chronic Illness, 19 DEV. \& BEHAV. PEDIATRICS 68 (1998).

52. Id. at 69 .

53. Id. at 74 .

54. Id. at 68,74 . The authors' definition of "imminent justice" appears on page 68 of their article.

We incorporated their definition into the quote for purposes of clarity (emphasis in original).

55. Id. at 75 (emphasis in original).

56. $I d$. at 75 . 
dren's medical knowledge..$^{57}$ In their study, Herbst describes the three- and four-year-olds as the "younger children," while the five- and six-year-olds are the described as "older children." Herbst wrote:

[O]ur data indicate that young children are more likely to report painful than benign touch and that they understand the necessity to provide an accurate narrative to persons in authority. This suggests that, compared to [three- and four-year-old] children, [five- and six-year-old] children were better able to distinguish what kinds of events merit possible concern and need an adult's attention and acknowledgment. They often mentioned the presence of blood as a reporting requirement. The [five- and sixyear-old] children, in determining whether or not to tell a doctor, also made the discrimination between self-inflicted injury and injury caused by another-and were more likely to report the latter. These findings parallel research on children's highly accurate reports of painful medical procedures and suggest that even some very young children have the capacity to meet the medical hearsay exception. ${ }^{58}$

\section{Herbst asked the children about lying to a doctor:}

Characteristic of the [three- and four-year-old] children were vague negative responses such as "You're in big trouble now" or punishments such as a time-out or a loud reprimand from the doctor. [Five- and six-year-old] children often thought that the doctor would become angry; eight [out of twenty older] children understood that the doctor would not be able to be helpful or would prescribe inappropriate treatment. ... [Three- and four-year-old] children's responses were characterized by centration and showed concern with possible punishment for lying. [Five- and six-yearold] children were beginning to express a discriminated perception wherein lying prevents the physician from being helpful or results in possible harm from inappropriate treatment.

Herbst concluded:

Both the three-to-four-year-olds and the five-to-six-year-olds could concretely describe what a physician does: [Five- and six-year-old] children were better able to describe concepts such as treatment and prevention functions and to identify the special knowledge associated with the physician's role than [three- and four-year-old] children. Neither group expected that the physician would know the cause of an injury without being told. Both age groups identified the truth as positive and [five- and sixyear-old] children tended to more readily identify lying as negative. [Five- and sixyear-old] children were significantly ${ }^{60}$ better than younger children at describing the concepts of truth telling and lying and could also better understand potential consequences of lying to a physician.

This brief review of the psychological literature yields several tentative conclusions. As would be expected, children do not possess adult-like knowledge of health and illness. Nor do children fully comprehend the roles of medical professionals. On the other hand, children as young as three and four years of age have a developing appreciation of the role of "doctor" and of the importance of telling the truth. As Herbst wrote, "even some very young children

57. See generally Melody R. Herbst et al., Young Children's Understanding of the Physician's Role and the Medical Hearsay Exception, in CHILDREN's UNDERSTANDING OF BIOLOGY AND HEALTH 235 (Michael Seigal \& Candida C. Peterson eds., 1999).

58. Id. at 247-48.

59. Id. at 250 .

60. The author uses the word "significantly" in the scientific sense, meaning statistically significant.

61. Herbst et al., supra note 57, at 253. 
have the capacity to meet the medical hearsay exception." ${ }^{\circ 2}$ It seems clear that with children under the age of roughly seven, a case-by-case assessment is needed to evaluate the child's understanding of the clinical importance of candor.

When we think about children and the medical diagnosis or treatment exception, we should also consider this analogous topic: children's knowledge of the legal system. ${ }^{63}$ Children do not have adult-like knowledge of the legal system and the roles of legal professionals. ${ }^{64}$ Ask a child the meaning of "court," and the reply is likely to be: "A place to play basketball." ${ }^{65}$ When asked the meaning of the term "arrest," a five-year-old answered, "It means you're lying down." When the court clerk told a child he could "take the witness stand," the youngster thought he was allowed take it home with him. ${ }^{67}$ Children's incomplete, and sometimes mistaken, understanding of the legal system does not mean they are incompetent to testify. By the same token, children's incomplete and sometimes mistaken understanding of the medical system does not mean they lack the incentive to tell the truth to the doctor. The important question is whether a particular child had the incentive to be truthful on a particular occasion.

Medical professionals are aware of the clinical importance of getting accurate information from patients. Most doctors and nurses are less cognizant, however, of the forensic reasons to ensure that children understand the need to be truthful. We urge training on this point for the professionals who examine and talk to children.

\section{F. Of Babies and Bathwater: What Does "Diagnosis" Mean in 803(4)?}

Rule 803(4) admits statements for treatment or diagnosis. Thus, statements to physicians who diagnose only are admissible for the truth. In the context of 803(4), the word "diagnosis" has at least two meanings, one of which is entirely consistent with the "patient incentive" rationale of Rule 803(4); the other meaning is not.

There are many occasions when patients have as much incentive to tell the truth to non-treating diagnosticians as to treating doctors. Consider radiologists. The patient on the $\mathrm{X}$-ray table does not expect treatment from the radiologist conducting the procedure and asking questions. ${ }^{68}$ Yet, the patient has

62. Id. at 248 .

63. See Ingrid M. Cordon et al., Children in Court, in AdVERSARIAl Versus INQuisitorial Justice: Psychological Perspectives on CRiminal Justice Systems (forthcoming) (on file with authors).

64. See 2 MYERS, supra note 5, at $\$ \S 6.40-6.47$.

65. See generally Karen J. Saywitz, Children's Conceptions of the Legal System: “Court is a Place to Play Basketball.”, in PERSPECTIVES ON CHILDREN's TESTIMONY 131 (Stephen J. Ceci et al. eds., 1989).

66. Michelle Aldridge et al., Children's Understanding of Legal Terminology: Judges Get Money at Pet Shows, Don't They, 6 CHILD ABusE REV. 141, 145 (1997).

67. $I d$.

68. We realize that intervention radiologists provide treatment. In most cases, however, the radiologist's role is limited to diagnosis. We also realize that, most of the time, a radiologist is not present 
every reason to be truthful. As another and very common example, treating doctors routinely obtain consultations from other doctors. The consultant's role is limited to diagnosis, yet the patient is motivated to tell the truth.

The "patient incentive" motive may be lacking when a patient/litigant hires a doctor for the sole purpose of diagnosing the patient's condition and providing expert testimony. Although we cannot say how often the incentive is missing in such circumstances, we believe that when a diagnostician is hired solely to testify, the patient/litigant's statements should be excluded from 803(4).

Because the word "diagnosis" has two meanings—one of which is consistent with the "patient incentive" rationale of 803(4), and another which isn't-condemning all statements to diagnosticians is similar to throwing the baby out with the bathwater. ${ }^{69}$ The key inquiry is to determine the patient's incentive, not to ask whether the doctor is a treater or a diagnostician.

The confusion generated by the multiple meanings of "diagnosis" will not be remedied by striking "diagnosis" from the Rule. ${ }^{70}$ The Rule can stay as it is if the bench and bar appreciate the dual meaning of "diagnosis." This is not to say that the language of $803(4)$ is perfect. We would prefer to see the Rule amended as follows:

The following are not excluded by the hearsay rule, even though the declarant is available as a witness: Statements made for purposes of medical treatment, including diagnosis and consultation for purposes of treatment, and describing medical history, or past or present symptoms, pain, or sensations, or the inception or general character of the cause or external source thereof insofar as reasonably pertinent to diagnosis or treatment.

\section{G. Stigmatizing Doctors in Hospital-Based Child Protection Centers}

A number of commentators imply that doctors who work in hospital-based child protection centers are little more than agents of the prosecution and that children's statements to such doctors should not be admitted under 803(4). ${ }^{71}$ Christopher Mueller is a dean of evidence, and we usually defer to him. In his superb treatise with Laird Kirkpatrick, however, we think the authors misstep when they write "that doctors and social workers who interview children shortly after abuse occurs often act almost as extensions of the offices of prosecutors

when X-rays are taken. An X-ray technician takes the film, and a radiologist reads it later. Nevertheless, there are procedures where the radiologist is present in the room conducting the procedure and interacting with the patient. Due to the joys of the aging process, the first author recently enjoyed a little time on the X-ray table swallowing quantities of delicious barium and answering a radiologist's questions. I had no desire to lie to the man.

69. See 4 MUELLER \& KIRKPATRICK, supra note 19, at $\$ 442$ (explaining that confusion over the word "diagnosis" is deepened when the authors write, "Statements for purposes of diagnosis offer no similar assurance of candor.").

70. Timothy Perrin suggests eliminating "diagnosis" from 803(4). See Perrin, supra note 25, at 996. We are inclined to believe Professor Perrin is only worried about the doctor/expert, but we are not certain from his article. See id. In any event, we disagree.

71. See Perrin, supra note 25, at 1013 ("The doctor, psychologist, or social worker who conducts the interview is often more like an agent of the police than a provider of medical treatment. To the extent the doctor is acting more like an investigator than a doctor, the child's statements certainly fall outside the contours of rule 803(4)."); see also Mosteller, supra note 22. 
and police, and in some urban hospitals special areas are set aside to collect statements by abuse victims in order to qualify them under the exception." though we concede there may be physicians who are "cops in white coats," we think it unfair to paint all hospital-based medical professionals with the same stigmatizing brush.

Although we have great respect for Professors Mueller and Kirkpatrick, we doubt they have spent much time interacting with the doctors and nurses who work in hospital-based child protection centers. Two of the present authors, on the other hand, have years of experience with such professionals. Perhaps it is our experience that causes us to have more faith. We believe that in many cases, children's statements to doctors working in hospital-based child protection centers have the indicia of reliability required by Rule 803(4). The fact that hospital-based professionals are aware of the forensic implications of their work does not transform them from doctors into detectives.

\section{H. Conclusion}

Psychology sheds valuable light on children's developing understanding of the importance of telling doctors the truth. Children as young as three and four can appreciate the significance of candor. Medical professionals should be trained to instill in young patients the incentive required by the medical diagnosis or treatment exception. With this exception, then, the ratio of intuition to psychological science has been adjusted in the direction of greater psychological understanding.

IV

\section{THE RESIDUAL AND CHILD HEARSAY EXCEPTIONS}

We turn next to the residual and child hearsay exceptions that exist in most states. The discussion is divided into two parts. In part one we discuss the Supreme Court's decision in Idaho v. Wright. ${ }^{73}$ In the second part we analyze the criteria used by courts to assess reliability, and the psychological science that bears on those criteria.

When a child's statement does not fit under a traditional hearsay exception, the hearsay may be offered under a residual or child hearsay exception. Under these exceptions the primary issue is reliability, and the starting place is Idaho $v$. Wright $^{74}$ In Wright, the Court ruled that reliability is assessed in light of "the totality of the circumstances." "75 The Court's "totality" approach was consistent with lower court precedent. In one respect, however, Wright veered away from precedent. The Court ruled that the circumstances that are relevant to reliability "include only those that surround the making of the statement and that ren-

72. 4 MUELLER \& KIRKPATRICK, supra note 19 , at $\S 442$.

73. Idaho v. Wright, 497 U.S. 805 (1990).

74. Id.

75. Id. at 819 . 
der the declarant particularly worthy of belief." ${ }^{\prime 6}$ A judge evaluating the reliability of hearsay may consider circumstances immediately surrounding the statement, but must ignore corroborating circumstances that do not surround it.

What circumstances immediately surround a child's statement? Wright provided examples, including spontaneity, consistency, motive to fabricate, and "use of terminology unexpected of a child of similar age." As for nonsurrounding corroboration, the Court mentioned medical evidence and the defendant's opportunity to abuse the child.

Wright's distinction between immediately surrounding circumstances, which may be considered in assessing reliability, and corroboration, which may not, is difficult to understand. Justice Kennedy dissented, along with Justices Blackmun, Rehnquist, and White. Justice Kennedy wrote:

The majority errs, in my view, by adopting a rule that corroboration of the statement by other evidence is an impermissible part of the trustworthiness inquiry. The Court's apparent ruling is that corroborating evidence may not be considered in whole or in part for this purpose. ... I see no constitutional justification for this decision to prescind corroborating evidence from consideration of the question whether a child's statements are reliable. It is a matter of common sense for most people that one of the best ways to determine whether what someone says is trustworthy is to see if it is corroborated by other evidence... ${ }^{78}$ The short of the matter is that both the circumstances existing at the time the child makes the statements and the existence of corroborating evidence indicate, to a greater or lesser degree, whether the statements are reliable. ...

To appreciate the difficulty created by Wright, consider a case in which a four-year-old's hearsay statement describes anal intercourse. An investigation reveals six circumstances: (1) the child's statement describing the abuse was spontaneous, (2) the child had no motive to lie, (3) the child's statement demonstrated developmentally unusual knowledge of anal intercourse, (4) medical examination a day later revealed a fresh laceration of the child's anus, (5) the defendant admitted that he did precisely what the child said he did, and (6) the day after the assault, the defendant was observed secretly disposing of the child's bloody underpants. Under Wright, only circumstances 1 through 3 immediately surround the child's statement. Items 4 through 6 must be ignored in the trial court's assessment of reliability. Yet, when is a trial judge justified in placing the most confidence in the child's statement? When all six circumstances are considered? Is it logical to place as much confidence in the statement when items 4, 5, and 6 are ignored? In general, the more evidence there is supporting a proposition-in this case reliability-the better. ${ }^{80}$ It is only logical to consider all six circumstances in the effort to assess reliability; it simply makes no sense to ignore three circumstances that may, in this case, provide the strongest evidence of reliability.

76. Id.

77. Id. at 821 .

78. Id. at 828 (Kennedy, J., dissenting).

79. See id. at 834 .

80. See Edmund M. Morgan, Basic Problems of Evidence 185-88 (1963). 
Our consternation with Wright's distinction between immediately surrounding circumstances and corroboration led us to empirical research in which we sought to determine whether jurors intuitively recognize and follow Wright's distinction. We realize, of course, that jurors do not apply Wright's distinction because jurors do not determine the admissibility of hearsay. Nevertheless, once hearsay is admitted, jurors decide whether to believe it. If jurors fail to grasp Wright's logic-if jurors think corroboration is useful in assessing reliability - then Justice Kennedy's already convincing argument is even stronger.

In our study, jurors in real child sexual abuse trials examined a list of circumstances that might affect reliability. ${ }^{81}$ Some of the circumstances on the list were of the "immediately surrounding" ilk; others were corroborative. Jurors ranked the degree to which particular circumstances helped in deciding whether to believe children. Jurors gave high rankings to numerous circumstances that Wright held must be ignored. For example, thirty-two percent of the jurors said medical evidence was important in believing the child. Fifty-one percent of the jurors indicated that the defendant's statements were important for their decision to believe the child. ${ }^{82}$ Jurors are instructed to use common sense, and the jurors in this study apparently thought it made sense to consider corroborating evidence in assessing hearsay.

\section{A. Circumstances Relevant to Reliability}

Courts consider numerous circumstances to determine the reliability of hearsay offered under the residual and child hearsay exceptions. We discuss a number of these circumstances below. We begin with legal principles, followed by information from the psychological literature.

\section{Testimonial Competence}

a. The law. The fact that a child was competent to testify at the time of an out-of-court statement can impact reliability. Competence at the time of the statement indicates the child possessed the ability to observe, remember, and relate events, as well as an understanding of the difference between truth and falsehood, at that time.

The impact on reliability of a lack of testimonial competence at the time of an out-of-court statement depends on the element of competence found wanting. If the child lacked understanding of the difference between truth and falsehood at the time of the statement, reliability may be diminished. On the other hand, if the child had difficulty communicating at that time, the impact on reliability may be minimal.

81. John E.B. Myers et al., Jurors' Perceptions of Hearsay in Child Sexual Abuse Cases, 5 PSYCHOL. PUB. POL'Y \& L. 388, 393 (1999). Jurors who volunteered to participate in the research were given a questionnaire after deliberations were complete and the jury rendered its verdict. Volunteers took the questionnaire home, filled it out, and mailed it to us. See id. at 393.

82. Id. 
Lack of testimonial competence at the time of trial may or may not impact reliability of hearsay. In Idaho $v$. Wright, the defendant argued that the child's out-of-court statements were unreliable because the trial judge found that the child could not communicate at trial. ${ }^{83}$ The Supreme Court rejected defendant's argument, writing:

[W] have in any event held that the Confrontation Clause does not erect a per se rule barring the admission of prior statements of a declarant who is unable to communicate to the jury at the time of trial.... Although such inability might be relevant to whether the earlier hearsay statement possessed particularized guarantees of trustworthiness, a per se rule of exclusion would not only frustrate the truth seeking purpose of the Confrontation Clause, but would also hinder States in their own "enlightened development in the law of evidence." ${ }^{84}$

It is important to ask why the child is incompetent to testify at trial. If the child lacks the ability to distinguish truth from falsehood, this "disability" may have existed at the time of the out-of-court statement. On the other hand, if the only reason the child cannot testify at trial is fear of the courtroom, the child's testimonial incompetence has no bearing on the reliability of hearsay. ${ }^{85}$

b. The psychology. Our legal system requires witnesses to be competent providers of information, that is, witnesses must be able to observe, remember, and recall the events in question. Witnesses must also be able to understand the difference between truth and falsehood and understand the obligation to tell the truth.

One of the requirements for competency is the capacity to remember and recollect the event or events under investigation. The child is not required to remember the event perfectly; rather, the child must possess some recollection of the event. The empirical research on children's memory is voluminous. ${ }^{86}$ The literature reveals that the majority of children have the capacity to recall accurate and relevant information. Several factors influence children's memory capacity, including the child's age, the complexity of the event, the child's familiarity with the event, and the delay between the event and the time at which the event is recalled. By age three, children can recall salient, personally significant events quite well. ${ }^{87}$ Nina Hamond and Robyn Fivush found that when young

83. 497 U.S. 805,824 (1990).

84. Id. at 825 .

85. See In re Lucero L., 998 P.2d 1019 (Cal. 2000); In re Cindy L., 947 P.2d 1340 (Cal. 1997); State v. Doe, 719 P.2d 554 (Wash. 1986).

86. See, e.g., CHILD VICTIMS, CHILD WiTnESSES: UNDERSTANDING AND IMPROVING Testimony (Gail S. Goodman \& Bette L. Bottom eds., 1993); SANDRA HewitT, AssEssing Allegations of Sexual Abuse in Preschool Children: Understanding Small Voices (1998) ("As early as 13 months, the capacity to construct and store memories of specific events is sufficiently developed to allow recall over extended times"); ("Research with children as young as 2 and 3 years of age has found that they could give intelligible and organized accounts of daily activities they had experienced, and they could also give accurate and detailed reports for novel, or one time events"); DEbra A. PoOle \& Michael E. LAmb, InVEstigative INTERVIEWS OF CHILDREN: A GUIDE FOR HELPING PROFESSIONALS (1998).

87. See Charles J. Brainerd \& Peter A. Ornstein, Children's Memory for Witnessed Events: The Developmental Backdrop, in THE SUGGESTIBILITY OF CHILDREN's RECOLLECTIONS 10 (John Doris ed., 1991); Michael J. Farrar \& Gail S. Goodman, Developmental Differences in the Relation Between 
children (between the ages of three and one-half and five) were questioned about a trip to Disney World that occurred either six or eighteen months earlier, all children, regardless of age, were able to recount a substantial amount of accurate information. ${ }^{88}$

A consistent finding in memory studies, however, has been that young children provide little information in response to open-ended or free-recall questions. Older children's reports tend to be more detailed than younger children's, and older children tend to report more spontaneous information than younger children. ${ }^{89}$ Although very young children typically provide less information, the information they provide tends to be accurate..$^{90}$ Since young children provide less spontaneous information as compared to older children and adults, young children often require more direct questions to elicit information, which may increase the risk of error in their statements. ${ }^{91}$

Psychologists have increasingly turned their attention to individual differences in children's memory. ${ }^{92}$ Gail Goodman and colleagues, for example, investigated individual differences in children's memory for a stressful medical procedure called voiding cystourethrogram fluoroscopy (VCUG). ${ }^{93}$ This procedure is used to examine children with urinary tract problems. The test involves the insertion of a catheter into the child's urethra. Through the catheter, the child's bladder is filled with fluid, which permits the urinary tract system to be photographed with X-rays as the child voids onto the examining table. The authors found that factors related to the child's family predicted children's memory errors and level of stress, and that greater prior knowledge of the VCUG procedure was associated with the number of correct responses to questions about the procedure. Children's emotional reactions also affected their

Script and Episodic Memory: Do They Exist?, in KNOwING AND REMEMBERING IN Young CHILDREN 30 (Robyn Fivush \& Judith Hudson eds., 1990); Judith A. Hudson \& Robyn Fivush, What Young Children Remember and Why, in KNOWING AND REMEMBERING IN YOUNG CHILDREN 1 (Robyn Fivush \& Judith Hudson eds., 1990).

88. See generally Nina R. Hamond \& Robyn Fivush, Memories of Mickey Mouse: Young Children Recount Their Trip to Disneyworld [sic], 6 COGNITIVE DEV. 433 (1991).

89. See id.; see also generally Peter A. Ornstein et al., Young Children's Long-Term Retention of Medical Experiences: Implications for Testimony, in MEMORY DEVELOPMENT: STATE OF THE ART AND FUTURE DIRECTIONS 349 (Franz E. Weinert \& Wolfgang Schneider eds., 1995).

90. See generally J. R. SPENCER \& RHONA FLIN, THE EVIDENCE OF CHILDREN: THE LAW AND THE PSYCHOLOGY (1990); Lynne Baker-Ward et al., Young Children's Long-Term Retention of a Pediatric Examination, 64 CHILD DEV. 1519 (1993); Hamond \& Fivush, supra note 88, at 433; Peter A. Ornstein, et al., Children's Memory for a Personally Experienced Event: Implications for Testimony, 6 APPLIED COGNITIVE PSYCHOL. 49 (1992).

91. See generally Hamond \& Fivush, supra note 88, at 433; see also Peter A. Ornstein et al., Young Children's Long-Term Retention of Medical Experiences: Implications for Testimony, in MEMORY DEVElopment: STATE OF THE ART AND Future DiReCTIONS 349 (Franz E. Weinert \& Wolfgang Schneider eds., 1995).

92. See generally Gail S. Goodman \& Jennifer M. Schaaf, Over a Decade of Research on Children's Eyewitness Testimony: What Have We Learned? Where Do We Go From Here?, 11 APPLIED COGNITIVE PSYCHOL. S5, S14 (1997).

93. See generally Gail S. Goodman et al., Children's Reactions to and Memory for a Stressful Experience: Influences of Age, Knowledge, Anatomical Dolls, and Parental Attachment, 1 APPLIED DEV. SCIENCES 54 (1997). 
memory. Children who were embarrassed about the procedure tended to provide fewer units of information in response to free-recall questions, whereas this was not the case for children who were proud of having undergone the procedure. Thus, individual-difference factors related to children's family, knowledge, and emotions may affect accuracy and completeness of the memory report. Although researchers have begun to study individual differences, much more information is needed to better ascertain how such factors influence children's ability to encode, retain, and recall information accurately.

Differentiating between truth and lies and understanding the obligation to tell the truth in court are also essential components of competency. Children do not need to comprehend the subtleties of truth and falsehood. Rather, what is required is a basic ability to discriminate between truths and lies. The child must also demonstrate an understanding that it is wrong to lie or that the child may be punished if he or she tells a lie. ${ }^{94}$

By the time they are four, most children understand the difference between truths and lies sufficiently to testify. ${ }^{95}$ In general, young children can distinguish between truths and lies, as well as between lies and mistakes if asked to do so in a concrete manner, using concrete examples. ${ }^{96}$ Kay Bussey, for example, found that young children could appreciate the "naughtiness" of lying, ${ }^{97}$ and Jeff Haugaard and colleagues found that most young children could understand that a child who made an inaccurate statement at the request of a parent or friend was telling a lie. ${ }^{98}$ Requiring children to define truths and lies, however, may understate their competence, especially with maltreated children who tend to lag behind in linguistic development. ${ }^{99}$ Thomas Lyon and Karen Saywitz found that maltreated children under seven years of age often could not define "truth" or "lie," nor were they able to distinguish between the two terms. ${ }^{100}$ Most children, however, were able to identify both truthful statements and lies, and they recognized that lying was wrong.

To be deemed competent, children must also understand the obligation to tell the truth and that untruthful testimony can result in punishment. The child

94. See generally Jeff J. Haugaard \& N. Dickon Reppucci, Children and the Truth, in COGNITIVE \& SOCIAL FACTORS IN EARLY DECEPTION 29 (Stephen J. Ceci et al. eds., 1992).

95. See Debra A. PoOle \& Michael E. LAmb, InVESTIGATIVE INTERVIEWS OF Children: A Guide For HelPING Professionals (1998); Thomas D. Lyon, Child Witnesses and the Oath: Empirical Evidence, 73 S. CAL. L. REV. 1017, 1037 (2000); see also generally Thomas D. Lyon \& Karen J. Saywitz, Young Maltreated Children's Competence to Take the Oath, 3 APPLIED DEV. SCI. 16 (1999).

96. See generally Michael Siegal \& Candida C. Peterson, Breaking the Mold: A Fresh Look at Children's Understanding of Questions about Lies and Mistakes, 32 DEV. PSYCHOL. 322 (1996).

97. See generally Kay Bussey, Children's Lying and Truthfulness: Implications for Children's Testimony, in COGNITIVE AND SOCIAL FACTORS IN EARLY DECEPTION 89 (Stephen J. Ceci et al. eds., 1992).

98. See generally Jeff J. Haugaard et al., Children's Definitions of the Truth and Their Competency as Witnesses in Legal Proceedings, 15 LAW \& HUM. BEHAV. 253 (1991).

99. See generally Debbie Hoffman-Plotkin \& Craig T. Twentyman, A Multi-Modal Assessment of Behavioral and Cognitive Deficits in Abused and Neglected Preschoolers, 55 CHILD DEv. 794 (1984); Thomas D. Lyon \& Karen J. Saywitz, Young Maltreated Children's Competence to Take the Oath, 3 APPLIED DEV. SCI. 16 (1999).

100. See Lyon \& Saywitz, supra note 99. 
does not need to understand or believe in divine punishment. Rather, the child must understand that punishment may come from any of a number of sources including God, judges, or parents. Many children are aware of the importance of telling the truth in court. Rhona Flin and her colleagues, for example, found that the common justification for honesty among six- to eight-year-olds was that lying could lead to being jailed or punished. ${ }^{101}$ By age ten, many children understand the importance of telling the truth to determine the guilt or innocence of a person.

In general, most children understand that telling lies can lead to negative consequences. For example, Candida Peterson, James Peterson, and Diane Seeto reported that children (ranging in age from five to eleven years of age) offered four types of consequences for lying: ${ }^{102}$ (1) punishment ("God gets angry at you," "You get into trouble/belted/sick"); (2) destruction of trust ("It's not fair," "People won't believe you next time"); (3) guilt ("You feel terrible"); and (4) don't know. ${ }^{103}$ Peterson and her colleagues also found that, whereas eleven-year-olds tended to justify the prohibition on lying in terms of trust and fairness, younger children mentioned punishment more often than eleven-yearolds.

Recently, Kay Bussey examined children's categorization and evaluation of different types of lies. ${ }^{104}$ Children ages four, eight, and eleven were read twelve vignettes of three different types of lies: antisocial lies (lies made to conceal a misdeed), white lies (falsehoods not meant to injure anyone), and trick lies (lies told for fun). ${ }^{105}$ The results of this study indicate that the children were able to categorize false statements as lies and true statements as truths. ${ }^{106}$ However, some differences between children of different ages were found. Categorization of false and true statements among four-year-olds varied across types of lies. ${ }^{107}$ Four-year-olds were more likely to classify false statements involving misdeeds as lies than false statements involving interpersonal (white lies) or pretend situations (trick lies). ${ }^{108}$ Regardless of context, older children were more likely to classify false statements as lies than younger children. ${ }^{109}$ Bussey suggests that, compared to older children, younger children may have more limited experience with white lies and, therefore, may have more difficulty categorizing interpersonal false statements as lies. ${ }^{110}$ In addition, parents may be more reluctant

101. See Rhona Flin et al., Children's Knowledge of Court Proceedings, 80 BRIT. J. PsYCHOL. 285 (1989).

102. See generally Candida C. Peterson et al., Developmental Changes in Ideas About Lying, 54 CHILD DEV. 1529 (1983).

103. See id.

104. See Kay Bussey, Children's Categorization and Evaluation of Different Types of Lies and Truths, 70 CHILD DEV. 1338 (1999).

105. Id. at 1339 .

106. Id. at 1345 .

107. Id.

108. Id.

109. Id. at 1343 .

110. Id. at 1343-44. 
to label such false statements as lies than when labeling false statements about misdeeds because parents sometimes implicitly encourage children to tell such lies out of concern for others. ${ }^{111}$ Bussey also found that children, regardless of age, were able to appreciate the wrongfulness of lying. ${ }^{112}$ Children across all age groups judged lying as being worse than truth-telling. ${ }^{113}$ Thus, research suggests that young children understand, although may not always be able to define, the difference between truth and lies. They are also able to appreciate the wrongfulness of lying compared to truth-telling.

\section{Spontaneity}

a. The law. Courts consider spontaneity to be an important indicator of reliability. Of course, spontaneity is not always indicative of reliability. As the Supreme Court noted in Idaho v. Wright, "it is possible that '[i]f there is evidence of prior interrogation, prompting, or manipulation by adults, spontaneity may be an inaccurate indicator of trustworthiness." ${ }^{114}$ Nevertheless, courts put considerable stock in the spontaneity of children's statements.

b. The psychology. In the psychological literature, the spontaneity of children's disclosures of sexual abuse has been a topic of much debate. One issue concerns the process through which children disclose victimization experiences, that is, how readily children disclose abuse. A related issue concerns parental questioning of children when abuse is suspected. We address each issue in turn.

Because disclosure by a child of abuse is the starting point for many investigations, one must understand how children typically disclose abuse. The picture that emerges from extant research, however, is far from clear. Early research was based largely on clinical observation of intrafamilial sexual abuse. This work suggested that disclosure is often delayed and halting. In 1983, Roland Summit described five aspects of children's disclosure of sexual abuse: ${ }^{115}$ (1) secrecy and unwillingness to disclose; (2) helplessness (feelings of being unable to alter the situation); (3) entrapment and accommodation (adjustment to the abuse); (4) delayed, conflicted, and unconvincing disclosure; and (5) retraction. In another early study, Teena Sorenson and Barbara Snow examined 116 cases from a larger sample of children who had received psychotherapy for sexual abuse. ${ }^{116}$ Sorenson and Snow's qualitative analyses suggest a disclosure process

111. Id. at 1344 .

112. $I d$.

113. See id.

114. Idaho v. Wright, 497 U.S. 805, 807 (1990).

115. See Roland Summit, The Child Sexual Abuse Accommodation Syndrome, 7 CHILD ABUSE \& NEGLECT 177 (1983).

116. See Teena Sorenson \& Barbara Snow, How Children Tell: The Process of Disclosure in Child Sexual Abuse, 70 CHILd WELFARE 3 (1991). 
similar to the one elucidated by Summit: denial, disclosure, recantation, and affirmation. ${ }^{117}$

Experimental and "scientific case studies" support the idea that the disclosure process may include delayed reporting, secrecy, and recantation. ${ }^{118}$ Even when children have no obvious motivation to conceal touch to their private parts, such as genital touch by a pediatrician in a medical setting, some children do not readily report genital touch in response to open-ended questions. ${ }^{119}$ Other researchers found low rates of initial denial of abuse and later recantation. April Bradley and James Wood, for example, found that among 234 children who were victims of sexual abuse, only six percent initially denied their victimization, and only three percent recanted their initial allegations. ${ }^{120}$

Many factors influence the disclosure process. For instance, age, relationship to the perpetrator, fear of negative consequences, and attribution of selfblame may influence the likelihood and process of disclosure. Regarding age, young children are generally less likely to disclose abuse to adults in a formal setting, even when the children have already made an initial disclosure to a parent or other adult. ${ }^{121}$ In addition, younger children appeared more likely than older children to make accidental disclosures, without clear intention of revealing the abuse. ${ }^{122}$

In addition to age, relationship to the perpetrator plays a role in children's willingness to disclose. For instance, Maria Sauzier found that children who had been allegedly abused by a natural parent or family member were particularly reluctant to disclose the abuse, whereas victims of extra-familiar abuse tended to reveal the abuse sooner after the incident. ${ }^{123}$ Sauzier also reported that the methods used by perpetrators to obtain victim compliance were related to the timing of the children's disclosures; only about twenty-five percent of children who had been psychologically manipulated and/or threatened by their abuser reported the abuse immediately. In a study involving children whose cases were prosecuted in criminal court, Tina Goodman-Brown found that chil-

117. See Lori S. Gonzalez et al., Children's Patterns of Disclosures and Recantations of Sexual and Ritualistic Abuse Allegations in Psychotherapy, 17 CHILD ABUSE \& NEGLECT 81 (1993).

118. See, e.g., Sue Bidrose \& Gail S. Goodman, Testimony and Evidence: A Scientific Case Study of Memory for Child Sexual Abuse, 14 APPLIED COGNITIVE PSYCHOL. 197 (2000).

119. See Karen J. Saywitz et al., Children's Memories of a Physical Examination Involving Genital Touch: Implications for Reports of Child Sexual Abuse, 59 J. CONSUlTING \& CLINICAL PSYCHOL. 682 (1991).

120. April R. Bradley \& James M. Wood, How Do Children Tell? The Disclosure Process in Child Sexual Abuse, 20 CHILd ABUSE \& Neglect 881 (1996).

121. See Kay Keary \& Carol Fitzpatrick, Children's Disclosure of Sexual Abuse During Formal Investigation, 18 CHILD ABUSE \& NEGLECT 543 (1994).

122. See Leslie Biron Campis et al., Developmental Differences, J. AM. ACAD. CHILD \& Adolescent PsychiAtry 920 (1993); see also Marcellina Mian et al., Review of 15 Children 6 Years of Age and Under Who were Sexually Abused, 10 CHILD ABUSE \& NEGLECT 223 (1986).

123. Maria Sauzier, Disclosure of Child Sexual Abuse: For Better or for Worse, 12 PsYCHIATRIC Clinics OF N. AM. 455 (1989). 
dren who feared negative consequences to others and who blamed themselves for the abuse were least likely to readily disclose their victimization. ${ }^{124}$

When children disclose sexual abuse spontaneously, they are most likely to do so to their mothers, although friends, relatives, and teachers are also frequent recipients of such unsettling news. Children often make disclosures in response to parental questioning once suspicion arises. ${ }^{125}$ Thus, it is important to consider the effects of parental questioning on children's accuracy. Recent research suggests that children may be less vulnerable to suggested responses when asked misleading questions by their mothers compared to unknown female interviewers. ${ }^{126}$ This result was also confirmed in a study by Shelly Jackson and Susan Crockenberg. In this study, preschoolers were interviewed by either their parent or a stranger, in either a misleading or non-misleading fashion. ${ }^{127}$ Results indicated that children in the misleading condition were more suggestible when misinformation was introduced by a stranger than by their parents. Nevertheless, misinformation from parents can, under certain circumstances, distort children's reports. ${ }^{128}$

In real cases, after interviewing their children, parents often tell investigators what their children disclosed. A recent study by Maggie Bruck, Stephen J. Ceci, and Emmett Francoeur investigating mothers' reports of their conversations with their children demonstrated that the parents' reports were accurate regarding the gist of what the child said, but imprecise regarding the exact questions asked and whether the questions were open-ended or somewhat leading. ${ }^{129}$ There was a tendency to indicate that questioning was more open-ended than it really was. ${ }^{130}$ This type of imprecision is not specific to mothers. Michael Lamb and his colleagues showed similar patterns for forensic interviewers. ${ }^{131} \mathrm{Al}$ though adults are quite adept at reporting the gist what a child said, they may not be as reliable at reporting how the information was elicited. ${ }^{132}$

Overall, regarding spontaneity and disclosure, it is hazardous to make definitive conclusions from existing research. Some children disclose easily and

124. See Tina B. Goodman-Brown, Why Children Tell: Disclosing Child Sexual Abuse (1995) (unpublished dissertation, California School of Professional Psychology (Los Angeles)) (on file with authors).

125. See Lucy Berliner \& Jon R. Conte, The Effects of Disclosure and Intervention on Sexually Abused Children, 19 CHILD ABUSE \& NEGLECT 371 (1995).

126. See Gail S. Goodman et al., Mother Knows Best: Effects of Relationship Status and Interviewer Bias on Children's Memory, 60 J. EXPERIMENTAL CHILD PSYCHOL. 195 (1995).

127. Shelly Jackson \& Susan Crockenberg, A Comparison of Suggestibility in 4-Year-Old Girls in Response to Parental or Stranger Misinformation, 19 J. APPLIED DeVElOPMENTAL PsyCHOL. 527 (1998).

128. See Debra A. Poole \& D. Stephen Lindsay, Children's Suggestibility, in MEMORY AND SUGGESTIBILITY IN THE FORENSIC INTERVIEW (M. Eisen et al. eds., 2001).

129. See generally Maggie Bruck et al., The Accuracy of Mothers' Memories of Conversations with their Preschool Children, 5 J. EXPERIMENTAL PSYCHOL.: APPLIED 89 (1999).

130. Id.

131. Michael Lamb et al., Accuracy of Investigators' Verbatim Notes of their Forensic Interviews with Alleged Child Abuse Victims, 24 LAw \& HuMAN BEHAV. 699 (2000).

132. See id. 
early, whereas others delay reporting and are reluctant to talk. Still others recant and deny that anything happened.

\section{Questioning: Children's Suggestibility}

a. The law. The reliability of a hearsay statement can be influenced by the questions that elicit it. As questions become suggestive and leading, reliability can suffer. Children's suggestibility, and the competence of interviewers are of immense concern to judges.

b. The psychology. The psychological literature contains a large and growing body of research on children's suggestibility. ${ }^{133}$ Social scientists have been interested in children's vulnerability to suggestion since the early $1900 \mathrm{~s}^{134}$ Hundreds of studies have been conducted since the late 1970's examining children's memory capacities and vulnerability to suggestion as these issues pertain to eyewitness testimony.

What conclusions can be drawn from these studies? The psychological literature on suggestibility does not reveal any simple relationship between age and suggestibility. Suggestibility is a complex process which is multiply determined by several factors including the interplay between cognitive, developmental, emotional, social, and situational factors. Despite the complexity of this issue, psychological research supports two broad conclusions.

First, young children, particularly preschoolers, are often more suggestible than are older children and adults. ${ }^{135}$ However, even preschoolers possess the capacity to resist suggestive questioning. ${ }^{136}$ Young children have been observed to recall highly accurate and forensically relevant information, even when highly suggestive techniques were used. ${ }^{137}$ The second finding from the psychological literature is that as children near adolescence, they approach adult levels of suggestibility. ${ }^{138}$ Although young children are more suggestible than older children and adults, research indicates that the degree of suggestibility varies considerably. ${ }^{139}$ Psychological research has begun to delineate the circumstances under which children experience greater or lesser degrees of suggestibility. ${ }^{140}$

133. See, e.g., Stephen J. Ceci \& Mary Lyn Crotteau Huffman, How Suggestible are Preschool Children? Cognitive and Social Factors, 36 J. AM. ACADEMy CHILd \& AdOLESCENT Psychiatry 948 (1997); Thomas D. Lyon, The New Wave of Children's Suggestibility Research: A Critique, 84 CORNELL L. REV. 1004 (1999); Jodi A. Quas et al., Individual Differences in Children's and Adults' Suggestibility and False Event Memory, 9 LEARNING \& INDIVIDUAL DIFFERENCES 359 (1997); Karen J. Saywitz et al., Interviewing Children In and Out of Court: Current Research and Practice Implications, in APSAC HANDBOOK ON CHILD MALTREATMENT (John E.B. Myers et al. eds., 2d ed. 2002).

134. See e.g., Gail S. Goodman, Children's Testimony in Historical Perspective, 40 J. SoC. IssUES 157 (1984).

135. See Stephen J. Ceci \& Maggie Bruck, The Suggestibility of the Child Witness: A Historical Review and Synthesis, 113 PSYCHOL. BULLETIN 403, 431 (1993).

136. See id. at 433.

137. Id.

138. See id. at 431-32.

139. See id. at 431 .

140. Id. at 432 . 
Children's memory performance during free recall, for example, is found to be highly accurate. ${ }^{141}$ As questioning becomes more specific, however, there is an increased risk of error. Studies that have examined children's memory have generally found that children are often least suggestible to questions about central actions of personally experienced events. ${ }^{142}$ In contrast, when children are questioned about peripheral details, particularly when the materials to be remembered are not personally meaningful, higher levels of suggestibility have been observed. ${ }^{143}$ When suggestive questions are kept to a minimum, children can be quite accurate. In this regard, Maggie Bruck, Stephen Ceci, and Helen Hembrooke state:

[U]nder certain circumstances children are capable of providing accurate, detailed, and useful information. For example, in many of our own studies [of suggestibility], children in the control group conditions (who were questioned in nonsuggestive interviews) often recalled events flawlessly. This indicates that the absence of suggestive techniques allows even very young preschoolers to provide highly accurate reports, although they may be sparse in the number of details. Also, the results of a number of studies of children's autobiographical recall or memory for events indicate that children's recall is at times highly accurate and at times quite detailed about a large range of events. What characterizes these studies is the neutral tone of the interviewer, the limited use of misleading questions (for the most part, if suggestions are used, they are limited to a single occasion), and the absence of the induction of any motive or bias for the child to make a false report. ${ }^{144}$

An important implication of studies that emphasize the strength of children's memories is that they highlight the conditions under which children should be interviewed if one wishes to obtain reliable reports. Again, when children are interviewed by unbiased, neutral interviewers, when the number of interviews as well as the number of leading questions are kept to a minimum, and when there is an absence of threats, bribes, and peer pressure, then children's reports are at considerably less risk for taint. ${ }^{145}$

141. Graham Davies et al., Close Encounters of the Witness Kind: Children's Memory for a Simulated Health Inspection, 80 BRIT. J. PsYCHOL. 415 (1989); Gail S. Goodman \& Vicki S. Helgeson, Child Sexual Assault: Children's Memory and the Law, 40 U. MIAMI L. REV. 181 (1985); Ornstein et al., supra note 89.

142. See generally Ornstein et al., supra note 89; Leslie Rudy \& Gail S. Goodman, Effects of Participation on Children's Reports: Implications for Children's Testimony, 27 DEV. PsYCHOL. 527 (1991); Karen Saywitz et al., Children's Memories of a Physical Examination Involving Genital Touch: Implications for Reports of Child Sexual Abuse, 59 J. CONSUlting \& Clinical PsyCHOL. 682 (1991); Ann E. Tobey \& Gail S. Goodman, Children's Eyewitness Memory: Effects of Participation and Forensic Context, 16 CHILD ABUSE \& NEGLECT 779 (1992).

143. William S. Cassel \& David F. Bjorklund, Developmental Patterns of Eyewitness Memory and Suggestibility: An Ecologically Based Short-Term Longitudinal Study, 19 LAW \& HuM. BEHAV. 507 (1995); William S. Cassell et al., Developmental Patterns of Eyewitness Responses to Repeated and Increasingly Suggestive Questions, 61 J. EXPERIMENTAL CHILD PSYCHOL. 116 (1996).

144. Maggie Bruck et al., Reliability and Credibility of Young Children's Reports: From Research to Policy and Practice, 53 AM. PSYCHOL. 136, 146 (1998).

145. Id. 
Researchers have increasingly turned their attention to the manner in which children are questioned. ${ }^{146}$ In general, when children are questioned competently, they can be reliable providers of information. Interviewers, however, differ in the ways in which they elicit information. As previously stated, young children tend to provide little information in response to open-ended questions, which often necessitates the use of more specific probes to elicit information. ${ }^{147}$ Interviewers use a variety of techniques to elicit more complete reports from young children, some of which may influence children's factual recall and interpretation of events. The risk of suggestibility effects increases when interviewers introduce more suggestive questioning techniques. Extensive use of misleading questions and the heavy reliance on yes/no question forms, for example, increase the risk of suggestion in young children. ${ }^{148}$

Social pressures that arise during the interview may also influence children's reports. Stephen Lepore and Barbara Sesco conducted a study in which they varied the style of the interview. Some interviews were incriminating, while others were more neutral relative to the incriminating interview style. In the incriminating condition, interview style was manipulated by having the interviewer reinterpret the child's responses to questions about the "suspect's" behavior. The suspect's behavior was reinterpreted as being wrong or "bad." In the neutral interviewing style, the interviewer did not reinterpret or comment on the child's responses. Lepore and Sesco found that children in the incriminating interview endorsed more negative statements about an innocent person than did children in the neutral condition. ${ }^{149}$

Selective reinforcement of children's responses has also been shown to influence suggestibility. In a recent study, Sena Garven and her colleagues reported that when children were reinforced for specific responses, children made significantly more false allegations than did children who were not reinforced for specific answers. ${ }^{150}$ In this study, children aged five to seven years in the reinforcement condition were praised by the interviewer when they answered "yes" to questions. ${ }^{151}$ When children answered "no," the interviewer expressed disappointment. Children who received reinforcement made thirty-five percent false allegations whereas children in the control condition made false allegations twelve percent of the time. ${ }^{152}$

Creating an "atmosphere of accusation" may also increase the risk that children will make errors. In one study, Gail Goodman and her colleagues created

146. See, e.g., Stephen J. Ceci \& Richard D. Friedman, The Suggestibility of Children: Scientific Research and Legal Implications, 86 CORNELL L. REV. 33 (2000); Thomas D. Lyon, The New Wave in Children's Suggestibility Research: A Critique, 84 CORNELL L. REV. 1004 (1999).

147. See supra Part IV.A.1.b.

148. Debra A PoOle \& Michael E. LAMB, InVESTIGATIVE INTERVIEWS OF CHILDREN (1998).

149. Stephen J. Lepore \& Barbara Sesco, Distorting Children's Reports and Interpretations of Events Through Suggestion, 79 J. APPLIED PSYCHOL. 108 (1994).

150. Sena Garven et al., Allegations of Wrongdoing: The Effects of Reinforcement on Children's Mundane Fantastic Claims, 85 J. APPLIED PSYCHOL. 38 (2000).

151. Id. at 39 .

152. Id. at $42-45$. 
an atmosphere of accusation by telling children that they would "feel better once you've told," and asking them "are you afraid to tell?" 153 Children in this study were questioned about an event that had taken place four years earlier. ${ }^{154}$ The results indicated that children made a variety of errors in attempting to recall the event and in answering questions, suggesting that the interviewer's tone and urgency may cause children to make erroneous claims about events for which they have very little memory. ${ }^{155}$

Thus, research examining interviewing practices has shown that the ways in which children are interviewed play an important role in children's level of suggestibility. Highly suggestive interviewing techniques can increase suggestibility, even about central details of personally experienced events. ${ }^{156}$ These findings have led some researchers to conclude that "the degree to which children are suggestible depends to a large extent on how investigators conduct interviews." 157

Increased awareness that children's suggestibility "reflect[s] failures in the way adults listen to and question children" has led researchers to turn their attention to the frequency of these problematic interviewing techniques in actual cases. ${ }^{158}$ Only a few studies have systematically examined the frequency of problematic techniques in actual interviews. ${ }^{159}$ Amye Warren and her colleagues examined a sample of forty-two videotaped investigative interviews for the frequency of problematic techniques, including (1) suggestive questions, such as introduction of new information that the child has not provided; (2) social influence, such as telling the child that other people have already made allegations of abuse; (3) reinforcement, such as praise for abuse-related disclosures or criticism of children's responses; and (4) removal of the child from direct experience, that is, asking the child to pretend or speculate. ${ }^{160}$ Warren was permitted to examine videotapes of actual interviews conducted by child protective services workers. ${ }^{161}$ Children in the videotapes ranged in age from two to thirteen years. Overall, the results of the study were encouraging. War-

153. Gail S. Goodman et al., Nearly Four Years After an Event: Child Eyewitness Memory and Adult Perceptions of Children's Accuracy, 26 CHILD ABUSE \& NEGLECT (forthcoming 2002).

154. Id.

155. Id.

156. See Sean Garven et al., More than Suggestion: The Effect of Interviewing Techniques from the McMartin Preschool Case, 83 J. APPLIED PSYCHOL. 347 (1998).

157. Ceci, supra note 146, at 107.

158. See Poole, supra note 148.

159. Michael E. Lamb et al., Effects of Investigative Utterance Types on Israeli Children's Responses, 19 InT. J. BeHAV. DEV. 627 (1996); Amye R. Warren et al., "It Sounds Good in Theory, But. . " Do Investigative Interviewers Follow Guidelines Based on Memory Research?, 1 CHILD MALTREATMENT 231 (1996).

160. Amye R. Warren et al., Setting the Record Straight: How Problematic are "Typical" Child Sexual Abuse Interviews?, Paper Presented at the Biennial Meeting for the American Psychology-Law Society (March 2000) (on file with authors).

161. Id. 
ren found that the occurrence of the problematic techniques outlined above, when added together, was not high. ${ }^{162}$

In sum, questioning techniques can influence the degree to which children are suggestible. Although research has shown that children can provide accurate information, suggestive interviewing practices may threaten the reliability of children's statements. The extent to which these problematic interview techniques occur in child sexual abuse cases requires further investigation. The few extant studies provide some encouraging findings but firm conclusions must await further research.

\section{Consistency}

a. The law. Reliability can be enhanced when a child is consistent over time. If the child's description of abuse varies significantly with each telling, reliability (in the legal sense of the term) can suffer. Complete consistency is not required, however. Indeed, as explained below, a degree of inconsistency is normal in children.

b. The psychology. Psychological research offers a complex picture of consistency and its relation to accuracy. There are several reasons for inconsistency. One explanation is that the child is lying and can not keep the story straight. Although some children fabricate accusations, deliberate fabrication by children, particularly young children, appears to be very uncommon. ${ }^{163}$

Putting aside deliberate liars, what accounts for inconsistency in children who are trying to tell the truth? One explanation for inconsistency relates to the way some children disclose abuse. At first, a child may say nothing happened. ${ }^{164}$ Further questioning reveals a few details. As the questioning continues, even more details emerge. Finally, the child may recant and say nothing occurred, only to recant the recantation. Numerous other disclosure patterns occur. Clearly, it is important to find out why some children are inconsistent when describing abuse and to avoid jumping to conclusions.

It is common for children, particularly young children, to give slightly different versions of events each time they are questioned. Betty Gordon and Andrea Follmer observed that "[d] evelopmental research suggests that young children may be less consistent than older children in what they remember over a series of interviews." 165 Preschool children tend to be inconsistent when recounting their experiences mainly because the children recount new information in each interview. For example, Fivush and Hamond found that seventy-

162. Interviewers used problematic techniques in only " $8.6 \%$ of all the turns on average across all interviews." $I d$. at 6.

163. For the literature on fabricated allegations, see Myers, supra note 5, at $\S 5.5$.

164. Louanne Lawson \& Mark Chaffin, False Negatives in Sexual Abuse Disclosure Interviews: Incidence and Influence of Caretaker's Belief in Abuse Cases of Accidental Abuse Discovery by Diagnosis of $S T D, 7$ J. INTERPERSONAL VIOLENCE 532 (1992).

165. Betty N. Gordon \& Andrea Follmer, Developmental Issues in Judging the Credibility of Children's Testimony, 23 J. CLINICAL CHILD PSYCHOL. 283, 284 (1994). 
five percent of the information preschool children reported in a second interview was new. ${ }^{166}$ Despite the fact that the children were giving "inconsistent" versions, the information provided was quite accurate. ${ }^{167}$ When school-aged children were repeatedly questioned, their recall tended to be more consistent than that of preschoolers. ${ }^{168}$

Style of questioning is also relevant to consistency. When open-ended questions are asked of preschoolers, consistency is fairly low, yet accuracy is quite high. ${ }^{169}$ If specific questions are asked, both consistency and accuracy are typically found to be high, with some important exceptions, such as when specific yes/no questions are asked of very young children. ${ }^{170}$ Contrary to open-ended or free-recall questions that leave children free to choose what information to report, thus increasing inconsistency, specific questions provide children with a precise cue of what is to be recalled, promoting consistency. ${ }^{171}$ Consistency and accuracy, however, can be negatively affected by the type of questions asked. ${ }^{172}$ For instance, when preschoolers were asked misleading questions, they were sometimes less consistent over time and also less accurate. ${ }^{173}$

Despite its forensic relevance, consistency has rarely been studied in relation to real-world child abuse allegations. Ghetti, Goodman, Eisen, Qin, and Davis compared children's allegations of sexual and physical abuse across two interviews. ${ }^{174}$ Results revealed that older as opposed to younger children provided more consistent information in their reports of sexual and physical abuse. ${ }^{175}$ In addition, girls were more consistent than boys in sexual abuse reports. ${ }^{176}$

In sum, a degree of inconsistency is quite normal in children, especially preschoolers. Lack of consistency should not automatically undermine the reliability of a child's hearsay.

166. See generally Robyn Fivush et al., Content and Consistency in Early Autobiographical Recall, 14 DISCOURSE PROCESSES 373 (1991).

167. Id.

168. Judith A. Hudson \& Robyn Fivush, As Time Goes By: Sixth Graders Remember a Kindergarten Experience, 5 APPLIED COGNITIVE PSYCHOL. 347 (1991).

169. Robyn Fivush \& J.R. Shukat, Content, Consistency, and Coherence of Early Autobiographical Recall, in MEMORY AND TESTIMONY IN THE CHILD WITNESS (Maria S. Zaragoza et al. eds., 1995).

170. Robyn Fivush, Developmental Perspectives on Autobiographical Recall, in CHILD VICTIMS, CHILD WitNESSES: UNDERSTANDING AND IMPROVING TESTIMONY 1 (Gail S. Goodman \& Bette L.

Bottom eds., 1993).

171. See id.

172. See id.

173. Debra A. Poole \& Lawrence T. White, Effects of Question Repetition on the Eyewitness Testimony of Children and Adults, 27 DEV. PsYCHOL. 975 (1991); see also Debra A. Poole \& L.T. White, Tell Me Again and Again: Stability and Change in the Repeated Testimonies of Children and Adults, in MEMORY AND TESTIMONY IN THE CHILD WiTnESS 24 (Maria S. Zaragoza et al. eds., 1995).

174. Simona Ghetti et al., Consistency in Children's Reports of Sexual and Physical Abuse, 26 CHILD ABUSE \& NEGLECT (forthcoming 2002) (on file with authors).

175. Id.

176. Id. 


\section{Developmentally Unusual Sexual Knowledge}

a. The law. In Idaho v. Wright, ${ }^{177}$ the Court recognized that developmentally unusual sexual knowledge in a young child points toward reliability. Young children lack the experience to fabricate or fantasize detailed accounts of sexual acts. Naturally, one must take care to rule out benign explanations for a child's developmentally unusual sexual knowledge.

b. The psychology. Research on nonabused children's sexual knowledge has taken two forms: One method is to ask children what they know about sexuality (for example, where babies come from); another is to examine children's behavior. Not surprisingly, when children are asked about sexual knowledge, a developmental progression emerges: Young, nonabused children typically know little about adult sexuality. ${ }^{178}$ Some children have more sexual knowledge than others depending upon factors such as sex education by parents, siblings, or peers. Others have culturally related values or experiences and exposure to sexually tinged media. ${ }^{179}$

177. 497 U.S. 805 (1990).

178. Melissa M. Berends \& Sandra L. Caron, Children's Understanding and Knowledge of Contraception and Birth: A Developmental Approach, 20 J. SEX EDUC. \& THERAPY 18 (1994); RONALD J. GOLDMAN \& JULIET D. GOLdMAN, SHOW ME YOURS (1982).

179. See Berends \& Caron, supra note 178; see also Barbara Boat \& Mark Everson, Use of Anatomical Dolls in Sexual Abuse Evaluations: Current Research and Practice, in CHILD VICTIMS, CHILD WiTNESSES (Gail S. Goodman \& Bette L. Bottoms eds., 1993); Sonja N. Brilleslijper-Kater \& Herman E.M. Baartman, What Do Young Children Know About Sex? Research on the Sexual Knowledge of Children Between the Ages of 2 and 6 Years, 9 CHILD ABUSE REVIEW 166 (2000); Roberta Paikoff, Early Heterosexual Debut: Situations of Sexual Possibility During the Transition to Adolescence, 65 AM. J. ORTHOPSYCHIATRY 389 (1995). Brilleslijper-Kater and Baartman conclude their research with these comments:

The outcome of this study suggests that young children have very little sexual knowledge. They only possess a certain basic knowledge of genital differences, gender identity, sexual body parts and (non-sexual) functions of the genitals. Knowledge of pregnancy, birth, reproduction and adult sexual behaviour is very limited and decreases in the order listed. Only 5and 6-year-olds can tell us something about these areas, but their knowledge is still very limited. Younger children generally know less than older ones. 2-year-olds know less than each of the other age groups in all assessed areas of sexuality. As well as assuming that 2-year-olds really have less knowledge, verbal limitations should also be taken into account. These results are in agreement with other theoretical findings on the sexual development of children ....

Although parents nowadays consider it important to talk about sexuality even with young children, they still find it difficult to actually do so. Topics with which children are normally confronted, such as genital differences, pregnancy and birth, are easy for parents to discuss, whereas topics which are normally remote from children, such as sexual intercourse, sexual abuse and sexuality (not including reproduction), are considered to be difficult. This is for the most part attributable to the fact that children themselves appear to ask about things they notice which lead to curiosity, while they simply do not think about topics that do not occur in their lives. This also fits in with children's knowledge of differences between physical intimacy and sexual interactions. Children who have never been confronted with sexual abuse interpret daily intimate interactions between adults and children in terms of their own ('innocent') daily intimate sexual action experiences or curiosity and do not use sexual terms.

When comparing all the data presented in this article with statements of alleged sexually abused young children, who often appear to describe sexual interactions in a very vivid way, one can conclude that detailed sexual knowledge in young children should at least be regarded as a warning signal. Enlarging the group of non-abused children and comparing the 
Children's sexual behavior is another way to index sexual knowledge. William Friedrich and his colleagues gathered information on sexual behavior in nonabused children aged two through twelve. ${ }^{180}$ In 1990, Friedrich wrote that nonabused children "exhibit a wide variety of sexual behavior at relatively high frequencies, such as self-stimulatory behavior and exhibitionism." sexual behavior is normal during childhood, there are a number of behaviors that are quite unusual among nonabused children. Friedrich wrote that these unusual behaviors tend to be those "that are either more aggressive or more imitative of adult sexual behavior." "In In Friedrich's study, the sexual behaviors observed least often in nonabused children were: placing the child's mouth on a sex part; asking to engage in sex acts; masturbating with an object; inserting objects in the vagina or anus; imitating intercourse; making sexual sounds; French kissing; undressing other people; asking to watch sexually explicit television; and imitating sexual behavior with dolls. ${ }^{183}$ The fact that a child demonstrates one or more of these uncommon sexual behaviors, however, is not conclusive proof that their hearsay statements are reliable. Friedrich reminds us that "sexual behavior in children is related to the child's family context, most specifically, sexual behavior in the family." 184 Nevertheless, developmentally unusual sexual knowledge is a marker for sexual abuse.

In 1998, Friedrich and his colleagues updated their research on sexual behavior in nonabused children. ${ }^{185}$ The later research is consistent with the earlier work. Friedrich wrote that "[i]t is important to remember that children's behavior must be interpreted in light of individual and family variables. . . Although sexual behavior is normative, excessive sexual behavior appears related to other behavioral problems including sexual abuse."186

Friedrich is not alone in studying sexual behavior in children. The work of other researchers in the United States and Europe is consistent with Friedrich's findings. ${ }^{187}$

results with those of abused children will enable us to diagnose age-inappropriate and hence deviant sexual knowledge.

Id. at $177-78$.

180. See generally William N. Friedrich et al., Normative Sexual Behavior in Children, 88 PEDIATRICS 456 (1991).

181. Id. at 462 .

182. Id.

183. Id.

184. Id. at 463 .

185. William N. Friedrich et al., Normative Sexual Behavior in Children: A Contemporary Sample, 101 PEDiATRICS 9 (1998).

186. Id.; see also William N. Friedrich et al., Child Sexual Abuse Inventory: Normative, Psychiatric, and Sexual Abuse Comparisons, 6 CHILD MALTREATMENT 37 (2001).

187. See Brilleslijper-Kater, supra note 179; Jon R. Conte et al., Evaluating Children's Reports of Sexual Abuse: Results from a Survey of Professionals, 61 AM. J. ORTHOPSYCHIATRY 428 (1991); Marsha L. Heiman et al., A Comparative Survey of Beliefs About "Normal" Childhood Sexual Behaviors, 22 Child ABUSE \& Neglect 289 (1998); Frank Lindblad et al., Preschoolers' Sexual Behavior at Daycare Centers: An Epidemiological Study, 19 CHILd Abuse \& NEgLeCt 569 (1995); Susan Phipps-Yonas et al., Sexuality in Early Childhood, 23 CURA REPORTER 1-5 (1993); Eric Schoentjes et al., Child Sexual Behavior Inventory: A Dutch-Speaking Normative Sample, 104 PEDIATRICS 885 (1999); Robert Wells 


\section{Motive to Fabricate}

a. The law. Evidence that the child has a motive to lie impacts reliability. So, too, does evidence that an adult had a motive to coach or threaten the child.

b. The psychology. To be reliable, children must be able to speak the truth about events. If detected, untrue statements or any apparent motivation to lie, could discredit children's evidence. Legal scholars, psychologists, and the public in general often have conflicting beliefs about children's capacity to lie. For example, John Wigmore argued that children have a "childish disposition to weave romances and to treat imagination for verity." "Jean Piaget believed that children under eight years of age "spontaneously alter the truth and ... this seems to them perfectly natural and completely harmless." 189 When asked about the trustworthiness of children, college students believe that young children are highly prone to lie. ${ }^{190}$ Others, however, argue that children are too innocent to lie willfully and also lack the cognitive capacity or maliciousness to lie, particularly during testimony. ${ }^{191}$ Given these conflicting opinions, it is important to examine the extant data to determine whether or not young children have the capacity to lie. If so, one must examine what motivates young children to lie.

Establishing a definitive age for the emergence of lying is difficult. This is partly because most theoretically based research has focused on children's reasoning about lying rather than on children's production of lies. ${ }^{192}$ Some researchers who study children's understanding of the mental states of others (theory-of-mind researchers) have concluded that genuine deception is not possible until the age of four. This view is based on research indicating that most children under the age of four years are unable to pass false-belief tasks. Falsebelief tasks involve situations in which the child must understand that another person can hold beliefs that are inconsistent or contradictory to the actual state of reality. Theory-of-mind researchers argue that a child must first understand that others are capable of forming a false belief before the child can intentionally attempt to create a false belief through deceptive actions. For example,

et al., A Validation Study of the Structured Interview of Symptoms Associated with Sexual Abuse (SASA) Using Three Samples of Sexually Abused, Allegedly Abused, and Nonabused Boys, 21 CHILD ABuSE \& NEGLECT 1159 (1997); Robert D. Wells et al., Emotional, Behavioral, and Physical Symptoms Reported by Parents of Sexually Abused, Nonabused, and Allegedly Abused Prepubescent Females, 19 CHILD ABUSE \& NEGLECT 155 (1995).

188. John H. Wigmore, EVIDENCE IN TRIALS AT COMMON LAW 160 (1940).

189. JEAN Piaget, THE MORAL JudGMENT OF THE CHILD 166 (1965).

190. Michael E. Vasek, Lying as a Skill: The Development of Deception in Children, in DECEPTION: PERSPECTIVES ON HumAN AND Nonhuman DECEIT 271 (Robert W. Mitchell \& Nicholas Thompson eds., 1986).

191. See, e.g., Mary Ann Mason, A Judicial Dilemma: Expert Witness Testimony in Child Sexual Abuse Cases, 19 J. PSYCHIATRY \& LAW 185 (1991).

192. Carol S. Tate et al., Adults' Liability for Children's Lie-Ability: Can Adults Coach Children to Lie Successfully?, in COGNITIVE AND SOCIAL FACTORS IN EARLY DECEPTION 69 (Stephen J. Ceci et al. eds., 1992). 
Beate Sodian found that even simple deception was extremely difficult for three-year-old children. ${ }^{193}$ In a series of three experiments, children ages three to five years were asked to point deceptively to a pair of boxes, one of which contained golden stars and one which did not. ${ }^{194}$ Children were shown two puppets, a king (who would give the stars to the child) and a robber (who would keep the stars for himself). ${ }^{195}$ The child was to help the king obtain the stars, while preventing the robber from obtaining them. ${ }^{196}$ They could prevent the robber from obtaining the stars by deceptively pointing to the wrong box. ${ }^{197}$ The results indicated that only the four- and five-year-olds consistently deceived the robber puppet by pointing to the wrong box across two trials. ${ }^{198}$ Three-year-old children would often point to the correct box rather than deceptively to the empty box..$^{199}$

Anecdotal evidence, however, seems to contradict the assumption that children under the age of four are incapable of deception. Several studies of naturally occurring deceptive behaviors indicate that children younger than four engage in acts of deception. ${ }^{200}$ Paul Newton found that when parents of three- and four-year-olds were questioned about the age at which they believed children started to lie, most parents placed the age at three and one-half rather than four years of age. ${ }^{201}$ When parents were asked to rate specific detailed examples, lies from even younger children were rated by parents as deliberate lies. ${ }^{202}$

Studies conducted in a laboratory setting also found that children under four years of age are capable of deceptive behavior. Michael Lewis, Catherine Stanger, and Margaret Sullivan, for example, examined children's ability to intentionally hide their emotional expressions. ${ }^{203}$ Three-year-olds were instructed not to peek at a toy while the experimenter left the room. ${ }^{204}$ When the experimenter

193. Beate Sodian, The Development of Deception in Young Children, 9 BRIT. J. DEV. PsYCHOL. 173 (1991).

194. Id. at 185

195. Id. at 176-77.

196. Id. at 177 .

197. Id.

198. Id. at 185 .

199. Id. at $182-85$.

200. Suzanne Chevalier-Skolnikoff, An Exploration of the Ontogeny of Deception in Human Beings and Nonhuman Primates, in DeCEPTION: PERSPECTIVES ON HUMAN AND NONHUMAN DeCEIT 205 (Robert W. Mitchell \& Nicholas S. Thompson eds., 1986); JUDY DUNN, THE BEGINNINGS OF SOCIAL Understanding (1988); Judy Dunn, Young Children's Understanding of Other People: Evidence from Observations Within the Family, in CHILDREN's THEORIES OF MIND (Chris Moore \& Douglas Frye eds., 1991); Judy Dunn, Understanding Others: Evidence from Naturalistic Studies of Children, in NATURAl THEORIES OF Mind: Evolution, DEVElopment AND Simulation of Everyday MindREAding 51, 51 (Andrew Whiten ed., 1991); Peter LaFreniere, The Ontogeny of Tactical Deception in Humans, in MACHIAVELLIAN INTELLIGENCE: SOCIAL EXPERTISE AND THE EVOLUTION OF INTELlECT IN MONKEYS, APES, AND HumAns 238 (Richard W. Byrne \& Andrew Whiten eds., 1988); Michael E. Vasek, supra note 190.

201. Paul Newton et al., Children's Everyday Deception and Performance on False-Belief Tasks, 18

BRIT. J. DEV. PSYCHOL. 297 (2000).

202. See id.

203. Michael Lewis et al., Deception in 3-Year-Olds, 25 DEV. PSYCHOL. 439 (1989).

204. Id. at 440 . 
returned and asked the children if they had peeked, the majority (sixty-two percent) either denied that they had peeked or did not answer. ${ }^{205}$ Of those children who did not admit their transgression, sixty-one percent emphatically denied looking at the forbidden toy. ${ }^{206}$ Facial expression and bodily activity did not differentiate those children who attempted to deceive from children who told the truth. $^{207}$ The researchers concluded that deception strategies are adopted at early ages, and suggested that socialization factors may contribute to the development of deception strategies. ${ }^{208}$ For example, parents tell children not to lie, but both directly and indirectly, parents tell their children that deception is socially appropriate, such as when children are told to pretend to like a gift that they do not really like. ${ }^{209}$

A study by Michael Chandler, Anna Fritz, and Suzanne Hala, found that children as young as two and one-half could engage in a range of deceptive strategies. ${ }^{210}$ In this study, children aged two, three, and four were shown a board game in which children were encouraged to hide a "treasure" in one of several differently colored plastic containers with the aid of a puppet. ${ }^{211}$ The movements of the puppet could be tracked by a set of footprints that the puppet left on the board. ${ }^{212}$ Children were asked to hide the treasure in one of the containers and prevent one of the experimenters, who waited outside of the room, from finding the treasure as part of a game. ${ }^{213}$ At each trial, children were encouraged to use different strategies to deceive the experimenter. ${ }^{214}$ The deceptive options that children could engage in as part of the game strategy included: (1) withholding information; (2) wiping out the puppet's tracks in order to destroy evidence of the true hiding location; (3) openly lying about the location of the treasure by directing the experimenter to search in one of the empty containers; and (4) falsely nominating one or more of the empty containers as the true hiding place by either laying false tracks, or by both wiping up the true tracks and laying down a set of false tracks. ${ }^{215}$ The researchers found that children in all three age groups used each of the strategies available to them. ${ }^{216}$ There were no significant differences between age and the use of these deceptive techniques. ${ }^{217}$

205. Id. at 441 .

206. Id.

207. Id. at $440-41$.

208. Id. at 442 .

209. Id.

210. See generally Michael Chandler et al., Small-Scale Deceit: Deception as a Marker of Two-,

Three-, and Four-Year-Olds' Early Theory of Mind, 60 CHILD DEV. 1263 (1989).

211. Id. at 1269-70.

212. Id. at 1270 .

213. Id.

214. Id.

215. Id. at 1272 .

216. Id. at 1273 .

217. Id. at 1272-74; see also Suzanne Hala et al., Fledgling Theories of Mind: Deception as a Marker of Three-Year-Olds' Understanding of False Belief, 62 CHILD DEV. 83 (1991). 
In a recent article, Paul Newton, Vasudevi Reddy, and Ray Bull describe two studies of everyday deception in young children. ${ }^{218}$ In the first study, twenty-four mothers of three- to four-year-olds were asked to keep a diary of their children's apparent deceptive behaviors. Mothers were instructed in the kinds of behavior to be recorded and were reminded of these categories and examples prior to each observation period. Semi-structured interviews were also conducted with each mother every two weeks during the month-long observation periods. Fourteen forms of deception were identified during the observation periods, including false denials, false blame, false excuses, trickery, and false stories. From the fourteen forms of deception, five categories were identified: avoidance of discomfort (either physical or psychological), material gain, amusement, various, and unclear. During the observation periods, all children denied doing something that they were not supposed to do, all children faked an excuse to avoid doing something that they did not want to do, and all had faked an excuse in order to get something that they wanted. The majority of children attempted trickery (ninety-two percent), falsely blamed someone else (eighty-three percent), falsely claimed completion of a task (seventy-nine percent), and falsely claimed permission (sixty-seven percent). Although some deceptive responses were made in response to pressing questions and demands from mothers, other deceptive behaviors were found to be spontaneous and creative.

In a second study, the deceptive behaviors of a two-and-one-half-year-old were observed over a six-month period. As was found with the older children in the first study, the two-and-one-half-year-old child frequently used false denials and false permission assertions, but rarely lied in the form of false excuses. In addition, the child's deceptive behaviors were often observed to be spontaneous, generally appropriate to the situation, and involving the use of a variety of deceptive forms. Thus, we have some evidence that very young children are capable of various forms of deceptive behaviors, both verbal and non-verbal. Although it is still unclear when young children attain the ability to engage in higher order deception (inference of the mental states of others), young children do have some capacity to engage in sophisticated forms of deception. ${ }^{219}$

What are some factors that motivate children to engage in deceptions? Paul Ekman outlined several basic motivations for lying: to avoid punishment; to get something you could not otherwise get; to protect friends from trouble; to protect self or others from harm; to avoid embarrassment; to maintain privacy; and to demonstrate power over authority. ${ }^{220}$ Bella DePaulo and Audrey Jordan suggest that lies to avoid punishment emerge first, followed by lies aimed at attaining material gain, and lies of self-presentation. ${ }^{221}$ The study by Paul Newton

218. Newton, supra note 201.

219. Stephen J. Ceci \& Maggie Bruck, Suggestibility of the Child Witness: A Historical Review and Synthesis, 113 PSYCHOL. BULLETIN 403 (1993).

220. See generally PAUl EKMAN, Why KIDS LIE (1989).

221. Bella M. DePaulo \& Audrey Jordan, Age Changes in Deceiving and Detecting Deceit, in DEVELOPMENT OF NONVERBAL BEHAVIOR IN CHILDREN 151 (Robert S. Feldman ed., 1982). 
and colleagues provides some support for this assertion because the most frequent motivating factors observed in young children were found to be avoidance of punishment, material gain, and avoidance of embarrassment. ${ }^{222}$

A crucial question in the evaluation of children's testimony concerns the extent to which children can be motivated or coached to lie by an adult. To simulate more closely the conditions under which false allegations of abuse are made, Carol Tate and Amye Warren-Leubecker ${ }^{223}$ conducted a study to examine the extent to which children could be coached into giving false descriptions of events, and to examine children's ability to provide convincing coached descriptions to an adult who does not know that the child is lying. Forty children (between the ages of two and one-half and eight years) interacted with an experimenter with whom they had already become familiar. The experimenter told the children in the experimental condition (twenty children) that they should fool a second experimenter by lying about having played with a target toy that they had not played with. After the child consented, the experimenter and child rehearsed the story that they would tell the second experimenter. In the control condition (twenty children), children did play with the target toy. Fifteen of the children in the experimental condition agreed to play the trick; five children hesitated but then agreed to play the trick. Only twelve (sixty percent) of the children actually carried out the deceptive plan. Of these twelve children, two immediately told the interviewer the lie as she entered the room without being asked. One of the children spontaneously confessed during the specific questioning portion of the interview. One child confessed when asked "Is that what you really did?" Another child confessed as soon as the interview was completed. Thus, seven children (thirty-five percent) maintained the deception throughout. The children who carried out the deception throughout the experimental period were older children. It was found that the seven children who lied throughout the experiment provided significantly shorter descriptions of their activities than did control children. The authors concluded that children can be coached into providing deceptive information in the context of a trick, but that the coaching did not work well or last for very long in the majority of the children (sixty-five percent). The coaching worked best either with children who knew the co-conspirator well or with older children.

Jeff Haugaard and his colleagues examined how children define lying when the lie is made at the direction of a parent. ${ }^{224}$ The main question in this study was: "Do young children believe that if a parent tells them to make a particular statement, that statement is then true, whether or not it is accurate?"225 This is of concern because if the child comes to believe that a statement is true even when it is not, "the child could speak 'the truth' in a way that could mislead a

222. See generally Newton, supra note 201.

223. See generally Tate, supra note 192.

224. Jeff J. Haugaard et al., Children's Definitions of the Truth and Their Competency as Witnesses in Legal Proceedings, 15 LAW \& HUM. BEHAV. 253, 258 (1991).

225. Id. 
jury." ${ }^{226}$ Fifty-six preschool children, eighty-six kindergarten children, and twenty-three college students were shown one of two videotapes. The videos depicted a girl playing in a neighbor's pond. Previously, the child had been warned by the neighbor not to play in the pond. The neighbor finds the girl playing in the pond (approaching her to within four feet but never touching her) and tells her that he will report her to the police. The neighbor then sends her home. The girl returns home and eventually talks to a policeman. In one version of the video, the girl goes to her room and waits by herself for the policeman. In the second version, the girl goes to her room and speaks with her mother. The girl proceeds to tell her mother what occurred. The mother directs the girl to tell the policeman that the neighbor hit her. The results indicated that, among the child participants, twenty-nine percent stated incorrectly that the neighbor had hit the girl.

Another potential motivating factor in telling a lie was also investigatedlying to protect a friend. After the children participated in the video portion of the experiment, children were also instructed to read a vignette about a young girl who is told by her teacher that she must stay in the classroom instead of going to recess. The girl goes to recess anyway and plays with a friend. Later, the teacher asks the friend if the girl stayed in the classroom. The friend tells the teacher a lie in order to protect the girl. When children were asked if the friend had lied to the teacher ninety-one percent stated that the friend had lied, and nine percent indicated that the friend had told the truth. Although most children in this study correctly stated that making an inaccurate statement, either at the request of a parent or to protect a friend, is a lie, a small but nontrivial portion of children were influenced by parental direction or the desire to protect a friend.

Haugaard cautions, however, that this study cannot answer the question of how many children would actually lie at the direction of a parent, nor can this study answer the question of how many children would lie about a potentially serious event, such as abuse, at the direction of a parent. ${ }^{227}$ Therefore, care must be exercised when generalizing from this study to actual cases. The results from this study suggest, however, that parental directions to engage in deceptive behavior may have a strong influence on at least some children.

Finally, it is important to consider how skillful children are at lying. Some researchers have found age differences in deceptive ability, with older children tending to be more successful liars than younger children. Bella DePaulo and Audrey Jordan, for instance, found that young children (first graders) were unskilled liars. ${ }^{228}$ When young children lied, their true emotions often leaked out through facial expressions, body language, and tone of voice. ${ }^{229}$ Susan Leekam

226. Id.

227. See id.

228. Bella M. DePaulo \& Audrey Jordan, Age Changes in Deceiving and Detecting Deceit, in DEVELOPMENT OF NONVERBAL BEHAVIOR IN CHILDREN 151 (Robert S. Feldman ed., 1982).

229. See, e.g., Vasek, supra note 190. 
suggests that children become better at lying as they come to acquire higher order levels of deception. ${ }^{230}$ More research, however, is necessary to determine if there are developmental changes in the ability to lie convincingly.

In sum, even very young children engage in deceptive behaviors. They do so in response to motivating factors such as avoiding punishment, attaining material gain, and avoiding embarrassment. Children's skill at carrying out deception may increase with age, although few researchers have examined this issue systematically. At least some children's evaluations of truth-telling and lying may be influenced by parental direction, although how this generalizes to children's actual behavior, particularly in more serious cases of deception such as abuse, needs further study.

\section{B. Conclusion}

Idaho v. Wright's distinction between immediately surrounding circumstances and corroboration requires judges to close their eyes to evidence that can be highly probative of reliability. Hopefully, the Court will someday remove the distorting blinders imposed in Wright and put the "totality" back into "totality of the circumstances."

Psychological research sheds light on many of the circumstances that are relevant to reliability, and judges can use this research to inform their decisions. In the final analysis, however, decisions about reliability are exceedingly complex judgments that should be based not only on psychological science but also on experience, logic, and common sense. Psychology can inform the decisionmaking process, but cannot replace it.

\section{$\mathrm{V}$}

\section{A SAMPLE OF FIFTY CASES}

Do courts scrutinize children's hearsay statements carefully? Or do they "let it all in"? To gain a measure of insight into judicial handling of hearsay, we examined fifty appellate decisions from 1990 to $2000 .^{231}$ Thirty were state cases (sixty percent) and twenty were federal or military decisions (forty percent). All but three were criminal prosecutions. ${ }^{232}$ We limited our sample to child sexual abuse cases in which children's hearsay was offered under a medical diagnosis or treatment exception, a residual or child exception, or both. ${ }^{233}$ We located cases through Westlaw, employing various search terms. We included only cases where, in our judgment, the decision contained a useful discussion of

230. Susan R. Leekam, Believing and Deceiving: Steps to Becoming a Good Liar, in COGNITIVE AND SOCIAL FACTORS IN EARLY DECEPTION 47 (Stephen J. Ceci et al. eds., 1992).

231. 1990 - 4 cases; 1991 - 4 cases; 1992 - 8 cases; 1993 - 11 cases; 1994 - 5 cases; 1995-1 case; 1996-2 cases; 1997 - 1 case; 1998 - 3 cases; 1999 - 7 cases; 2000 - 4 cases.

232. The three non-criminal cases were juvenile court child protection cases.

233. We do not mean to say that other hearsay exceptions were not involved in the cases we examined. For example, some of the cases in our sample involved excited utterances, prior consistent statements, and so forth. The one constant in our sample was that every case involved the medical diagnosis or treatment exception, or the residual exception, or both. 
hearsay. As a result, many decisions were excluded where hearsay was mentioned only tangentially. Apart from excluding cases with superficial hearsay analysis, our overall goal was to obtain a relatively representative sample of cases from 1990 to 2000 . We realize that our sample of cases is not random in the scientific sense, and that our findings are subjective.

In our sample of fifty cases, there were fifty-six child victims. Children ranged in age from two to nineteen years. The average age was 6.8 years. Females comprised eighty-eight percent of the victims; males comprised twelve percent. Children testified in most cases. In thirteen cases (twenty-six percent), however, the child did not testify. ${ }^{234}$ When children did not testify, the most common reason was that the child was too young.

We were particularly interested in how often convictions were reversed because of the erroneous admission of hearsay. ${ }^{235}$ Margaret Berger pointed out that in the ordinary course of civil and criminal litigation, "an evidentiary error alone is not very likely to induce the reviewing court to term the error 'reversible." 236 Although Roger Park noted that "appellate courts produce an ample number of hearsay reversals," ${ }^{237}$ the odds of reversal on hearsay grounds are small. Professors Park and Steven Penrod examined hearsay issues in federal court from 1960 to 1988, and found that only one in 107 reversals was due to hearsay. ${ }^{238}$ A later study found that only one in 220 reversals was due to hearsay. ${ }^{239}$

The first author has been reading state and federal child abuse cases for years. The impression gained by such study is that reversals due to hearsay are not uncommon in child abuse cases. Professor Mosteller shares this impression. $^{240}$ In our sample of fifty cases, thirty-four (sixty-five percent) were affirmed; eighteen (thirty-five percent) were reversed. A reversal rate of thirtyfive percent seems high. For comparison, we examined fifty recent appellate court decisions involving rape of an adult. Ninety percent of the convictions were affirmed; ten percent were reversed. During the twelve-month period ending June 30, 1997, the reversal rate for all types of criminal cases in federal

234. In another study of actual court cases, the present authors and their colleagues examined fortytwo child sexual abuse trials in Arizona and California. In these cases, children testified in every case. John E.B. Myers et al., Jurors' Perceptions of Hearsay in Child Sexual Abuse Cases, 5 PsYCHOL. PUB. POL'Y \& L. 388 (1999).

235. The first author studied reversal rates in child sexual abuse prosecutions from 1900 to 1950. John E.B. Myers et al., Professional Writing on Child Sexual Abuse from 1900 to 1975: Dominant Themes and Impact on Prosecution, 4 CHILD MALTREATMENT 201 (1999). The reversal rate in child sexual abuse cases over these decades was similar to the reversal rate for other crimes. See id.

236. Margaret A. Berger, When, If Ever, Does Evidentiary Error Constitute Reversible Error?, 25 LOY. L.A. L. REV. 893, 895 (1992).

237. Roger C. Park, Hearsay, Dead or Alive?, 40 ARIZ. L. REV. 647, 648 (1998).

238. Id.

239. Id.

240. See Mosteller, supra note 22, at 60. 
court was $9.1 \%{ }^{241}$ Wayne LaFave and Jerold Israel estimate that the reversal rate for all crimes "tends to fall within the range of 10-20\%." ${ }^{242}$

We examined the eighteen cases in our sample that were reversed to see how many of the reversals were due to hearsay. Twelve of the eighteen reversals (sixty-seven percent) were due to error regarding hearsay. The fact that sixty-seven percent of the reversals in our sample were due to hearsay appears to indicate a rather high reversal rate. In our survey of the fifty rape cases involving adult victims, hearsay almost never figured in the court's decision to reverse.

Of course, our sixty-seven percent hearsay reversal statistic must be regarded with caution. We selected cases in which courts devoted more than passing attention to hearsay. It is likely that a court that is troubled by hearsay, and that is on its way to reversal on that ground, will devote more time to the subject than a court less preoccupied. Despite this caveat, our examination of these fifty cases, coupled with fifteen years of reading appellate cases on hearsay, leads us to conclude that in the context of child abuse, courts police the hearsay rule with care. Indeed, we believe that during the past five years, courts have become increasingly strict about children's hearsay.

\section{VI}

\section{CONCLUSION}

Psychology and law are strange bedfellows. Psychological science is based on empiricism and the scientific method. Law grows from experience and logic. ${ }^{243}$ Until recently, hearsay exceptions partook entirely of law, unsullied by psychological science. This is no longer the case. Modern psychological science sheds increasing light on the criteria used to determine the admissibility of hearsay. We see no reason to bemoan this development. Indeed, the law should welcome reliable insights from psychology. Will the day arrive when psychological science entirely replaces legal analysis in hearsay decision making? We doubt it. The rationale behind excited utterances has not been tested empirically, and may be difficult to put to the scientific test. Decision making under this exception rests on an intuitive guess about trauma and truth.

Turning to the medical diagnosis or treatment exception, whether or not children of different ages understand the significance of telling the truth to doctors is subject to empirical analysis and has been studied. Thus, psychology provides valuable age-specific information. Here, too, however, individualized judgment is required. The question in every case is whether this particular child understood the need for candor. Psychology can inform us about children in

241. Administrative OfFice of the United States Courts, Statistical Tables for the FEDERAL JUDICIARY, Table B-5 (1997).

242. WAYNe R. LAFAVE \& Jerold H. IsRael, CRiminal Procedure 29 ( $2 \mathrm{~d}$ ed. 1992).

243. With apologies to Justice Holmes, who said that "[t]he life of the law has not been logic: it has been experience.” Oliver W. Holmes, JR., The COMMON LAw 5 (Howe ed., 1963). 
general, but cannot tell us whether a particular child was motivated to tell the truth on a particular occasion.

As for the residual and child hearsay exceptions, psychology sheds light on several of the circumstances related to reliability. Whether hearsay is sufficiently reliable to gain admission in evidence, however, is too complex a matter to be reduced to a formula.

In recent years, the ratio of intuition to psychological science has adjusted slightly in the direction of science, although hearsay remains five parts law to one part psychology. The ratio will undoubtedly see further adjustment in the future.

It is fashionable among academics to criticize courts. We have done so ourselves by questioning the Supreme Court's distinction between circumstances that immediately surround out-of-court statements and circumstances that "merely" corroborate. Putting criticism aside, however, we believe that during the past twenty years, American courts have done a good job implementing the hearsay rule and its exceptions. Mistakes have occurred, but that is true in all areas of law, not just evidentiary rulings in child abuse cases. In our experience, judges in these difficult cases take the hearsay rule seriously, and try their best to be fair. Given the complexity of the task, the courts deserve high marks. 